\title{
Control of branches distribution in linear PE copolymers using fibrillar nanoclay as support of catalyst system
}

\author{
Paolo Tanasi $^{\text {a,b, }}$, María Asensio ${ }^{\text {b }}$, Manuel Herrero ${ }^{\text {a }}$, Karina Núñez ${ }^{\text {a,b }}$, Esteban Cañibano ${ }^{\text {a,b }}$, \\ Juan Carlos Merino ${ }^{\mathrm{a}, \mathrm{b}}$ \\ ${ }^{\text {a }}$ Foundation for Research and Development in Transport and Energy (CIDAUT), Parque Tecnológico de Boecillo, 47051, Valladolid, Spain \\ ${ }^{\mathrm{b}}$ Department of Condensed Matter Physics, Escuela de Ingenierías Industriales, University of Valladolid, Paseo del Cauce 59, 47011, Valladolid, Spain
}

\section{A R T I C L E I N F O}

\section{Keywords:}

Branches

Polyethylene (PE)

Copolymer

Nanocomposites

In situ polymerization

\begin{abstract}
A B S T R A C T
This study focuses on evaluating the consequences of using of sepiolite as a filler and co-catalyst support in the polymerization of polyethylene copolymers and their nanocomposites. The method used, in situ polymerization, has many variables to study because the type and distribution of the branches have an important effect on the final properties of the material.

In an effort to understand the influence of these variables, different polyethylene copolymers (hexene, octene, decene), with its respective nanocomposites, were prepared and characterized. Preliminary results have demonstrated the use of sepiolite allows obtaining nanocomposites with narrower molecular weights and a more homogeneous distribution of the branches than the corresponding neat copolymers.
\end{abstract}

\section{Introduction}

Polyolefins are thermoplastic polymers with a simple structure and with high demand due to the facility to produce and process them in a very economical way. The main uses of the polyolefins are limited to commodity applications such as manufacturing pipes, industrial parts, packaging, etc and their demand in applications for high performance is very low due to their properties are not enough in these areas. To widen the usefulness of polyolefins, nanocomposites are synthesized to improve the properties of the neat polymers [1].

Nanoscale fillers have at least one characteristic length scale of the order of nanometers and their morphologies can vary from isotropic to anisotropic. Due to the relative environmental impact and low cost, the nanoclays are used to form nanocomposites consisting of an organic polymer matrix dispersed with inorganic filler. Nanoclays are nanoparticles of layered mineral silicates with layered structural units that can form complex clay crystallites by stacking these layers [1-3].

The processing method is critical to obtain good quality and highperformance nanocomposite. The most important challenges of synthesis are to achieve good chemical compatibility between the polymer matrix and the nanofiller at the nanoscale and homogeneous dispersion of the nanofiller within the matrix. All these conditioning factors are related to the performance of the nanocomposites. There are three synthesis methods developed for the preparation of polymer nanocomposites: melt-mixing, solution-mixing, and in-situ polymerization. Melt-mixing is the most common method extensively used in the industry to obtain nanocomposites. This method is based on the traditional methods of polymer processing; however, sometimes materials with poor mechanical properties are obtained due to a low interfacial tension between the components. Solution-mixing promotes the dispersion of the nanoparticles in a solution containing the solubilized polymer matrix. The main disadvantage is the large quantities of solvent used in this method. In-situ polymerization is a highly effective method to obtain nanocomposites; in this method, the nanofiller is dispersed in the monomer and then the polymerization is performed. The monomer with the metallocene-based catalyst is intercalated into the nanofiller to start the polymerization process on it; the polymer chains exfoliate the nanofiller into layers allowing a better dispersion and also improving the compatibilization with the matrix without the use of compatibilizers. Despite the melt-mixing method is used specifically when working with polyolefins, the in-situ polymerization is widely applied because provides homogeneous dispersion and it is easy to modify by changing the polymerization conditions. Also, the in-situ polymerization allows the molecular designs of the polymer matrix [2,3].

Copolymerization of ethylene with small hydrocarbon chains, as hexene, is performed using catalyst Ziegler-Natta or metallocene. For

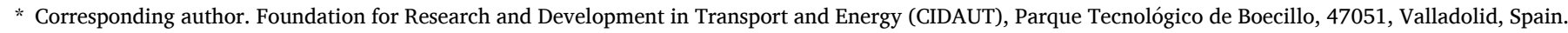

E-mail addresses: paotan@cidaut.es, paolo.tanasi@alumnos.uva.es (P. Tanasi).
} 
economic reasons, the Ziegler-Natta catalyst has a dominant position in the market; however, it has the disadvantage of producing copolymers with inhomogeneous branching distribution in his structure, which reduces the mechanical properties. This fact is due to the catalyst has different active species during the synthesis [4]. Metallocene catalysts and methylaluminoxane (MAO) as a cocatalyst have gained the commercial interest for olefin polymerization; however, the homogeneous catalysts have two major disadvantages: the lack of morphology control and reactor fouling. These drawbacks are overcome by binding the metallocene catalysts onto inorganic supports as supported metallocene catalysts. Many metallocene catalysts have been supported on inorganic carriers, typically silica. There are four main routes for the immobilization of metallocene catalyst: (i) Immobilization of metallocenes on $\mathrm{SiO}_{2}$. (ii) Immobilization of $\mathrm{MAO}$ on $\mathrm{SiO}_{2}$, followed by supporting metallocene. (iii) Immobilization of metallocenes on $\mathrm{SiO}_{2}$, followed by treating with MAO, and (iv) Immobilization of metallocene ligands on $\mathrm{SiO}_{2}$, followed by adding zirconium compounds [5-7].

The first attempt for the production of filled polyolefins with the treatment of the filler surface with metallocene-based catalysts has demonstrated to be an interesting point to copolymerize ethylene with $\alpha$-olefins [8]. The stereospecificity of the metallocene catalyst has a unique active site, allowing synthesize polymers with narrow molecular weight distribution and thus with homogeneous branching distributions $[9,10]$. This advantage has meant that in recent years the use of metallocene-based catalysts has grown up significantly for ethylene copolymer synthesis $[11,12]$.

Research in this field is still focused on improving the industrial use of these catalysts in terms of productivity, efficiency, thermal stability, rates in production processes, etc. The importance of advancing in these studies lies in the increasing amount of ethylene copolymers claimed (15 $\times 106$ tons per year). The main applications are films, pipes, containers, insulation, etc $[13,14]$.

It is known that the development of supported metallocene systems is crucial for the industrial application of these catalysts; mainly due to industrial processes only consider processes in suspension and/or gas phase. Our method can contribute to this field because catalysts supported on nanoscale particles have shown the best results in terms of the activity of copolymerization and best structures of the copolymers obtained [14-16].

The present procedure uses the sepiolite as support and filler [17], this fact affects final polymer structure. Consequently, this method has many variables to study, because the type and distribution of the branches have an important effect on nanocomposite properties [18].

This paper was designed to study the influence of the amount of nanoclay in the copolymerization of ethylene/hexene. Finally, given the importance of the length of branches on the final properties of the copolymer, three different co-monomers (hexene, octene, and decene) with an equal concentration of sepiolite and co-monomer were studied.

\section{Experimental}

\subsection{Materials}

Manipulations of air or moisture-sensitive were carried out under a controlled atmosphere. The clays used for the preparation of metallocene PE nanocomposites were a commercial sepiolite (SEP) supplied by TOLSA (unit fiber size $0.2-3 \mu \mathrm{m}, 10-30 \mathrm{~nm}$ width, and 5-10 nm in thickness), the physical-chemical properties of the sepiolite fiber bundles are shown in Table 1 [19]. These fillers were dried under vacuum at $80{ }^{\circ} \mathrm{C}$ for $24 \mathrm{~h}$ before treatment. Bis(Ciclopentadienyl)Zirconium (IV) dichloride, $\mathrm{Cp}_{2} \mathrm{ZrCl}_{2}$, used as catalyst was purchased from Aldrich and used as received. Methylaluminoxane (MAO, $17 \mathrm{wt} \%$ solution in toluene, AzkoNobel) was used as co-catalyst. Toluene was freshly dried by distillation from sodium-benzophenone under the nitrogen atmosphere. Polymerization purity grade ethylene supplied by Air Liquide was used after passing by an oxy trap and molecular sieve to remove
Table 1

Physico-chemical properties of sepiolite for fiber bundles.

\begin{tabular}{clll}
\hline & Composition & $\begin{array}{l}\text { BET } \\
\text { Specific } \\
\text { surface area } \\
(\mathrm{m} 2 / \mathrm{g})\end{array}$ & $\begin{array}{l}\text { Average particle } \\
\text { size }- \text { laser } \\
\text { granulometry }(\mu \mathrm{m})\end{array}$ \\
\hline $\begin{array}{c}\text { Physical- } \\
\text { chemical } \\
\text { properties }\end{array}$ & $\begin{array}{l}\text { Magnesiun silicate } \mathrm{Si}_{12} \mathrm{O}_{30} \\
\mathrm{Mg}_{8}(\mathrm{OH})_{4}\left(\mathrm{H}_{2} \mathrm{O}\right)_{4} \cdot 8 \mathrm{H}_{2} \mathrm{O}\end{array}$ & 319 & 12,69 \\
& $\begin{array}{l}\mathrm{Impurities:} \mathrm{Al}_{2} \mathrm{O}_{3}<5 \%, \\
\mathrm{Fe}_{2} \mathrm{O}_{3}<2 \%\end{array}$ & $50 \%<8,71 \mu \mathrm{m}$ \\
\hline
\end{tabular}

oxygen and water. The co-monomers: 1-hexene, 1-octene, 1-decene (99\% purity grade) were supplied by Sigma-Aldrich.

\subsection{Clay pre-treatment}

The desired amount of dry clay was mixed with co-catalyst, in ratio 2 $\mathrm{g}$ clay/ml of MAO solution, in $100 \mathrm{ml}$ of dry toluene and afterward the mixture was stirred for $90 \mathrm{~min}$ at room temperature, following the procedure explained in our previous work for optimizing the process of immobilization of the MAO in sepiolite $[1,17,20]$ The resulting solid was washed three times with $30 \mathrm{ml}$ of fresh toluene and dried inside globe box until it was used.

\subsection{Polymerization}

The polymerization method was based on a non-isothermal process; ethylene copolymers and their nanocomposites were carried out in a $1 \mathrm{~L}$ stainless steel autoclave equipped with a mechanical stirrer under the conditions explained in WO2013167764 A1 [1].

\subsection{Preparation of test specimens}

A Schwabenthan vacuum press and a home-made mold were used for compression molding of sheets $\left(1.5 \times 200 \times 200 \mathrm{~mm}^{3}\right)$. The polymer (dry powder samples) was stabilized with $0.5 \mathrm{wt} \%$ of a mixture of Irganox 1010 and Irgafos 168 (1:1) to prevent oxidative and thermal degradations. An internal mixer was employed to homogenize the polymer powder and the stabilizers. The fusion was carried out at 190 ${ }^{\circ} \mathrm{C}$, the frequency of the rotors was set at $60 \mathrm{rpm}$ and the polymer was melted and mixed for $5 \mathrm{~min}$.

The molding cycle was as follows: the melt polymer kept into the mold for $3 \mathrm{~min}$ without pressure at $190{ }^{\circ} \mathrm{C}$ and compressed for $5 \mathrm{~min}$ at $190{ }^{\circ} \mathrm{C}$. The molded sheets were cooled down to room temperature using an internal cold water circuit. The samples were cut accordingly to the requirements for each test characterization.

\subsection{Characterization}

In a polymerization process, the most important characteristic parameter is productivity. The productivity was measured as (kilograms of polyolefin $) /(\mathrm{Zr}$ moles * pressure * time).

The melt and crystallization temperatures $\left(\mathrm{T}_{\mathrm{m}}, \mathrm{T}_{\mathrm{c}}\right)$, as well as the heat of fusion $\left(\Delta \mathrm{H}_{\mathrm{m}}\right)$ and degree of crystallinity of samples $\left(\mathrm{X}_{\mathrm{c}}\right)$, were measured by a Mettler Toledo DSC 821e thermal analysis system model (DSC) in the temperature range from 25 to $200{ }^{\circ} \mathrm{C}$ at a heating rate of 20 ${ }^{\circ} \mathrm{C} \mathrm{min}^{-1}$ under nitrogen flow. The samples were first heated to $200{ }^{\circ} \mathrm{C}$ for $2 \mathrm{~min}$ to eliminate their thermal history and subsequently cooled to $25^{\circ} \mathrm{C}$. The second endotherm was recorded by heating $20^{\circ} \mathrm{C} \mathrm{min}{ }^{-1}$, the $\mathrm{X}, \mathrm{T}_{\mathrm{m}}$, and $\Delta \mathrm{H}_{\mathrm{m}}$ of the samples were calculated, taking the melting heat of neat PE as $293 \mathrm{~J} / \mathrm{g}$, [21]. The successive self nucleation and annealing (SSA) [22-27] experiment was carried out establishing self-nucleation isothermal steps for $5 \mathrm{~min}$ at a temperature which decreased $5{ }^{\circ} \mathrm{C}$ each step. Thermogravimetric Analysis (TGA) was used to determine the clay content in the obtained nanocomposites. Thermograms were obtained in a nitrogen atmosphere with a heating rate of $20^{\circ} \mathrm{C} \mathrm{min}-1$ using 
a Mettler Toledo TGA851e.

To analyze the morphology of the nanocomposite, the surface of the obtained powder sample was observed by scanning electron microscopy (SEM) in a Hitachi S-4700 Electron Microscope with an accelerating voltage of $20 \mathrm{kV}$, after coating with gold. Transmission electron microphotographs (TEM) were taken from $100 \mathrm{~nm}$ microtomed sections of the composites cut with a Reichert-Jung Ultracut E microtome using a JEOL JEM 2000FX Electron Microscope with an accelerating voltage of $200 \mathrm{kV}$.

Fourier Transform of Infrared Spectroscopy (FTIR) was used to identify the molecular vibrations produced by the absorption of infrared radiation on a sample. This technique allowed a qualitative identification of the species present through the characteristics bands in the vibrational spectra of the samples. These measurements were used a Bomen Hartman and Braun FTIR spectrometer, model MB-155, and a total attenuated reflectance accessory (ATR). Also, the FTIR spectra have been useful to make a semi-quantitative analysis of the comonomer content in the copolymers. It was correlated the peaks absorbance between 1378 and $1369 \mathrm{~cm}^{-1}$ that belongs to the symmetric deformation of the methyl end-group of 1-hexene units and the latter belongs to the methylene wagging [28].

These results were also confirmed in the most representative samples by ${ }^{13} \mathrm{C}$ NMR tests. ${ }^{13} \mathrm{C}$ NMR tests were performed on a $500 \mathrm{MHz}$ NMR Spectrometer (Bruker Avance III 500, 11.74 T). The ratio obtained of $A_{1378} / A_{1369}$ in the FTIR spectra was known as "R", then $R$ was calculated for each copolymer synthesized and has been related to the grafted comonomer molar percentage obtained by ${ }^{13} \mathrm{C}$ NMR tests.

The melt flow index was determined by measuring the polymer fluidity in the molten state at $190{ }^{\circ} \mathrm{C}$ and $2.16 \mathrm{Kg}$ according to ISO 1133 . The density was determined through of liquid immersion under the standard ISO 1183-1.

Molecular weight distributions were determined with a Waters ALLIANCE GPCV 2000 gel permeation chromatographer (GPC). 1,2,4trichlorobenzene was used as a solvent, at a flow rate of $1 \mathrm{~cm}^{3} \mathrm{~min}^{-1}$. The nanocomposites were dissolved and filtered through a $0.45 \mu \mathrm{m}$ PTFE filter to remove the solid particles. The analyses were performed at $145{ }^{\circ} \mathrm{C}$.

The mechanical properties of the resulting nanocomposites were measured as follows: Young's modulus at a speed of $1 \mathrm{~mm} \mathrm{~min}^{-1}$ and tensile strength at a speed of $50 \mathrm{~mm} \mathrm{~min}^{-1}$ was measured according to UNE-EN ISO 527-1 and 527-2 with an Instron Model 5500R60025.

\section{Results and discussion}

\subsection{PE/hexene nanocomposites: influence of the amount of hexene}

It has been demonstrated, in our previous work, that the sepiolite used presents high acidity due to their hydroxyl groups (-OH) which act as Brønsted acids which react with the methyl-aluminum (Me-Al)- like bonds present in MAO to form a covalent bond, aluminum-oxygen (Al-O), and thus obtaining the anchor. The vibration related to the $\mathrm{Si}-\mathrm{O}-\mathrm{Al}$ bond $\left(1015 \mathrm{~cm}^{-1}\right)$ present in the treated sepiolites was identified by FTIR as proof of the effective covalent binding between the MAO and the Silanol groups on the surface of the sepiolite [20]. This clay pre-treatment includes the co-catalyst heterogenization instead of the catalyst heterogenization as in most of the studies and it was based on the known techniques of the catalyst support.

It aimed to anchor the co-catalyst onto an inorganic substrate to give greater stability and efficiency to the catalyst during the reaction. In addition, the clay is incorporated in larger amounts than usual because it has to perform the catalyst heterogenization and reinforce the final compound. In Fig. 1, it is shown the TEM microphotographs of the PE nanocomposite with sepiolite where it can be seen a good dispersion and distribution of the fibrillar clay in the nanocomposites [17].

The success of this treatment is not only due to the amount of cocatalyst anchored, but also due to the MAO that once it is supported

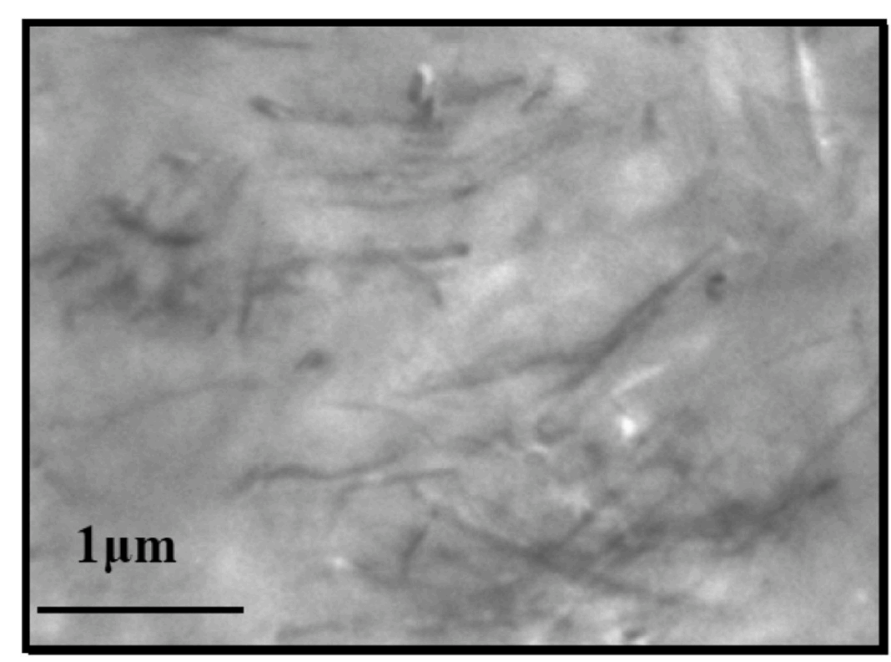

Fig. 1. TEM microphotographs of PE nanocomposites with sepiolite.

remains available to form the active species in presence of the metallocene catalyst during polymerization. Also, in our previous work, Fig. 2, it is shown the SEM micrograph for the nanocomposites powders and it can be observed that they have a needle-like structure. Based on the "replication of morphologies" this needle-like structure could be due to a replication of the fibrillar structure of sepiolite. The lengths of these needles are on the same order of nanometers [1].

To analyze the incorporation of small size ethylenic sequences, the sepiolite amount was fixed. Four PE/Hexene copolymerization were made with a range of comonomer concentration from $0.07 \mathrm{M}$ to $0.30 \mathrm{M}$ and $2 \mathrm{~g}$ of modified sepiolite (2:1) as it was described in the experimental section.

Table 2 shows a comparison of the thermal properties of PE/Hexene copolymers and their nanocomposites with the neat homopolymer. The first observation corresponds to the increase in productivity when a higher amount of comonomer is added. This phenomenon, known as "comonomer effect" has been described by other authors [29-34].

In the homopolymerization of the nanocomposites performed In Situ, the highly crystalline polymeric chains are synthesized around catalyst molecules. The monomer diffuses very slowly through the crystalline zone until finding the catalyst and keeps going the polymerization process. The addition of a small part of the co-monomer decreases the polymer crystalline zone formed, and it raises the probability for the monomers to find the catalyst and increase the polymerization productivity. For the copolymerization process, the increase in productivity has also been explained by the idea that the co-monomer incorporation can modify or raise the catalyst active centers during the reaction.

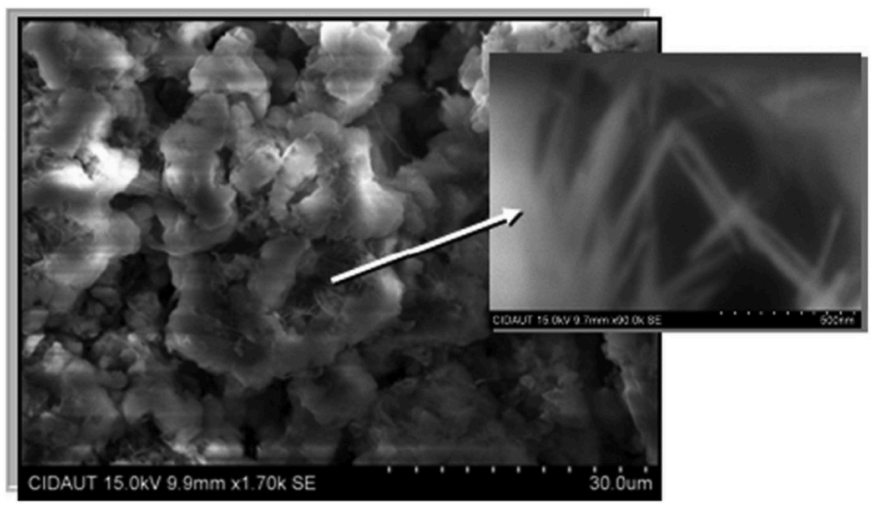

Fig. 2. SEM micrograph of the nanocomposite powders for a polyethylene nanocomposite. 
Table 2

Thermal and morphological properties of the different synthesized copolymers.

\begin{tabular}{|c|c|c|c|c|c|c|c|}
\hline & Sample ${ }^{a}$ & $\operatorname{Tm}\left(0,1 \pm{ }^{\circ} \mathrm{C}\right)$ & $\mathrm{Tc}\left(0,1 \pm{ }^{\circ} \mathrm{C}\right)$ & $\Delta \mathrm{Hf}(29 \pm \mathrm{J} / \mathrm{g})$ & $\mathrm{Xc}(0,1 \pm \%)$ & $\%$ clay & Productivity $^{\mathrm{b}}$ \\
\hline \multirow[t]{5}{*}{ Neat Copolymer } & $P E$ & 139.8 & 108.0 & 284 & 96.9 & - & $8.51 \times 10^{3} \pm 4 \times 10^{2}$ \\
\hline & СоHO.07 PE & 126.4 & 105.1 & 229 & 85.8 & - & $9.73 \times 10^{3} \pm 2 \times 10^{2}$ \\
\hline & СоHO.10 PE & 124.7 & 104.3 & 208 & 79.8 & - & $1.37 \times 10^{4} \pm 5 \times 10^{2}$ \\
\hline & СoHO.20 PE & 118.8 & 100.8 & 191 & 75.7 & - & $1.52 \times 10^{4} \pm 2 \times 10^{2}$ \\
\hline & СоHO.3O PE & 117.5 & 94.3 & 169 & 67.9 & - & $1.89 \times 10^{4} \pm 1 \times 10^{3}$ \\
\hline \multirow[t]{5}{*}{ Nanocomposite } & $N 2 P E$ & 144.1 & 108.8 & 254 & 92.1 & $3.5 \pm 0.7$ & $9.12 \times 10^{3} \pm 6 \times 10^{3}$ \\
\hline & N2CoHO.07 PE & 131.2 & 108.5 & 199 & 71.3 & $3.3 \pm 0.2$ & $1.04 \times 10^{4} \pm 4 \times 10^{3}$ \\
\hline & N2CoHO.1O PE & 128.3 & 105.0 & 187 & 67.6 & $3.0 \pm 0.4$ & $1.57 \times 10^{4} \pm 9 \times 10^{2}$ \\
\hline & $\mathrm{N} 2 \mathrm{CoHO} .20 \mathrm{PE}$ & 122.4 & 103.3 & 163 & 62.9 & $2.4 \pm 0.3$ & $1.44 \times 10^{4} \pm 8 \times 10^{3}$ \\
\hline & N2CoHO.3O PE & 117.7 & 101.2 & 142 & 59.9 & $1.5 \pm 0.1$ & $1.84 \times 10^{4} \pm 9 \times 10^{2}$ \\
\hline
\end{tabular}

a Nomenclature: PE: Polyethylene matrix, CoH0.07: hexene copolymer with $0.07 \mathrm{M}$ of initial hexene, N2: nanocomposite with $2 \mathrm{~g}$ of initial clay.

b $\mathrm{Kg}_{\mathrm{PE}} /\left(\mathrm{mol}_{\mathrm{Zr}} \cdot \mathrm{bar} \cdot \mathrm{h}\right)$.

Also, it is important to highlight that the degree of crystallinity reported was based on an "overall degree of crystallinity" using as the reference to the melting enthalpy of fusion for $100 \%$ crystalline PE. The contribution of the comonomer has been ignored in the calculation method because its effect on the degree of crystallinity will not alter in great proportion the reported values. In Fig. 3, it can be observed a comparison of the nanocomposite products obtained by homopolymerization and copolymerization. The presence of an $\alpha$-olefin in the reaction medium produces a more soluble amorphous polymer and increases the number of active centers during polymerization $[4,35]$.

Considering that the productivity increases with the comonomer amount added, the final clay in the nanocomposite is lower due to more copolymer is produced. This is shown as the final percentage of clay for the nanocomposites in Table 2. On the other hand, the nanocomposites' productivity is higher than the corresponding neat copolymers but the growth rate is slower. This fact is due to the negative component of $-\mathrm{OH}$ groups of nanofiller, although the "comonomer effect" is strongest in these cases. Comparing the productivity of homogeneous and heterogeneous polymerization systems, it is known that immobilize the supported co-catalyst on a substrate leads to high productivity due to better thermal stability and this is independent of the comonomer effect. However, speaking about the immobilization of the supported catalyst is different from a copolymerization whose support substrate is used in large quantities to also act as filler. Greater amounts of sepiolite lead to a lower reactivity rate due to a high concentration of heteroatoms in the reaction medium. Also, it was demonstrated that the volume of the MAO molecule hinders its interaction with all $-\mathrm{OH}$ groups present in the clay and not all molecules of MAO react with the clay surface $[1,13,17]$.

DSC tests (Fig. 4) show that increasing the amount of hexene causes a decrease in the enthalpy of fusion and crystallinity degree. This

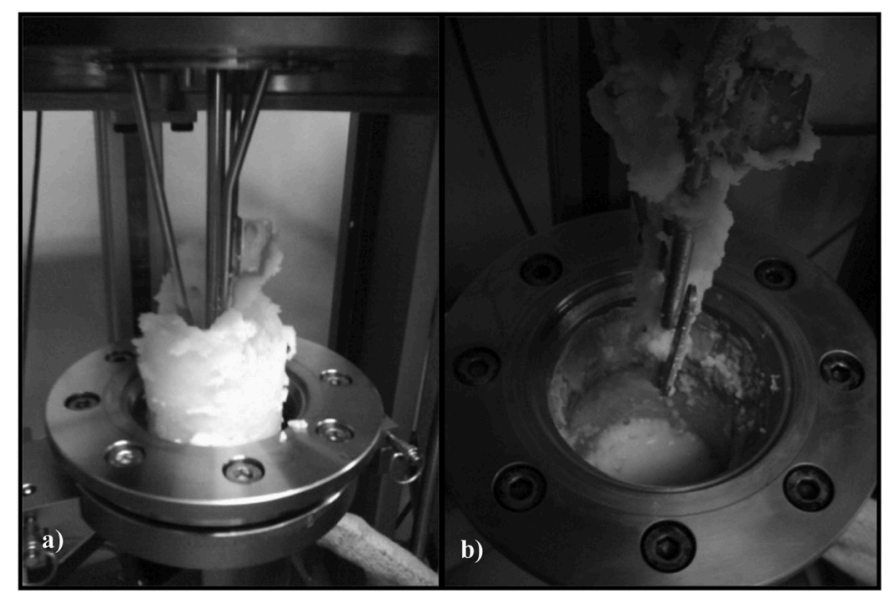

Fig. 3. Physical state of nanocomposites obtained in homopolymerization (a) and copolymerization (b). phenomenon reveals the growth of the amorphous region in the neat copolymer and nanocomposites with the increase of hexene [7].

Increasing the amount of hexene causes a reduction in the final amount of sepiolite, producing changes in the micro and macrostructural properties of nanocomposites ethylene/hexene. To study these changes, different parameters were measured (Table 3).

The decrease of molecular weight, in neat copolymers, when increasing the amount of hexene has been widely reported and is due to the transfer and termination reactions that promote the grafted branches [36]. The same behavior repeats in the nanocomposites, although it can be appreciated the increase of molecular weight in comparison to neat copolymers. When the polymerization is carried out on metallocenes immobilized in a nanoscopic space, the active species are protected from other chemicals that can cause transfer and termination reactions [37].

Another important aspect is that the raise in the molecular weights of the nanocomposites, against the neat copolymers, is parallel to the increase of hexene incorporated in nanocomposites. This phenomenon is caused by the immobilization of the catalyst in the support. In these cases, the incorporation of co-monomers is usually more effective [31, 38] and therefore bigger amount of hexene is incorporated in the chain.

Other evidence of the increase in the effective insertion of comonomer is the different peaks appearing in crystallization endotherms (Fig. 4b), as a result of new active sites that are capable of forming, in a simple sweep of heating and cooling, two different crystalline sections.

Successive self-nucleation and annealing (SSA) curves are shown in Fig. 5 and clearly evidence the increase of the amount of hexene promotes polymer segments that crystallize at lower temperatures. The new chains form crystals with lower lamellar thickness and melting temperature (Melting results showed in Table 2).

The comparison between neat copolymer and their nanocomposites shows that higher amounts of $0.07 \mathrm{M}$ of hexene displace the fusion to lower temperatures. These observations allow concluding that low concentrations of hexene, give the chains greater mobility, and therefore the ramifications can be nucleated by the sepiolite. Conversely, at high concentrations of co-monomer, the reaction increases their ability to incorporate branches increasing the amorphous region. It could be appreciated the narrowing effect on the melting endotherms in nanocomposites compared to neat copolymers. This phenomenon is caused by the better uniformity of the crystal sections, thus a great homogeneous distribution of branches on the structure of the copolymer is obtained.

Also in Table 3 regarding the branch distribution index and the weight-average of branches according to the percentage of added comonomer, the results confirm that nanoclay allows a bigger number of ramifications and incorporating them more equitatively.

Considering the results it is clear that increasing the concentration of hexene in nanocomposites copolymerization, the molecular weight loss is more controlled due to two effects: control of termination reactions by sepiolite and more homogeneous distribution of the comonomer in the polymer structure. This can be also seen by GPC tests (Fig. 6) in which it 


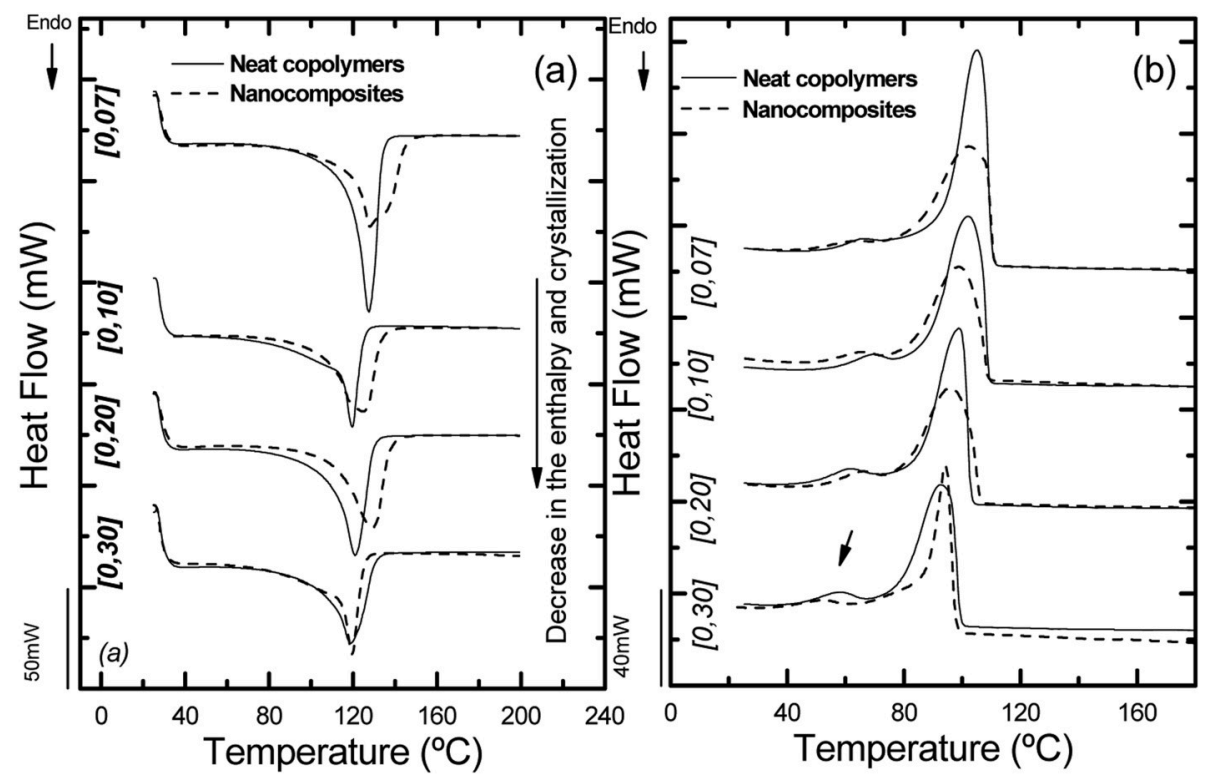

Fig. 4. DSC curves for a) fusion and b) crystallization of neat copolymer PE/Hexene and their nanocomposites.

Table 3

Structural characterization of neat copolymers and their nanocomposites with different amounts of hexene.

\begin{tabular}{|c|c|c|c|c|c|c|c|}
\hline \multirow[t]{6}{*}{ Neat Copolymers } & Sample & $\operatorname{Mv}( \pm 1,0 \times 103 \mathrm{~g} / \mathrm{mol})^{a}$ & $\operatorname{MFI}( \pm 0,3 \mathrm{~g} / 10 \mathrm{~min})^{\mathrm{b}}$ & $\%$ molar Hexene $( \pm 0,06)^{c}$ & $\operatorname{Cn}( \pm 0,02)^{d}$ & $\mathrm{Cw}( \pm 0,02)^{\mathrm{e}}$ & BDI $( \pm 0,9)^{f}$ \\
\hline & $P E$ & - & 9.7 & 0.00 & - & - & - \\
\hline & СоHO.O7 PE & $6,0 \times 10^{4}$ & 10.3 & 0.80 & 6.3 & 10.4 & 1.6 \\
\hline & СoHO.10 PE & $5,4 \times 10^{4}$ & 18.4 & 1.54 & 8.3 & 14.9 & 1.8 \\
\hline & СоHO.20 PE & $4,8 \times 10^{4}$ & 24.6 & 2.87 & 6.4 & 18.5 & 2.9 \\
\hline & СoHO.30 PE & $4,3 \times 10^{4}$ & 35.3 & 5.96 & 9.2 & 30.2 & 3.3 \\
\hline \multirow[t]{5}{*}{ Nanocomposites } & $N 2 P E$ & - & 7.3 & 0.00 & - & - & - \\
\hline & N2CoHO.07 PE & $7,7 \times 10^{4}$ & 9.1 & 0.92 & 10.1 & 12.1 & 1.2 \\
\hline & N2CoHO.10 PE & $6,5 \times 10^{4}$ & 16.4 & 2.25 & 12.3 & 16.0 & 1.3 \\
\hline & N2CoHO.2O PE & $6,2 \times 10^{4}$ & 22.3 & 4.47 & 13.8 & 20.6 & 1.5 \\
\hline & N2CoHO.3O PE & $5,8 \times 10^{4}$ & 29.9 & 8.76 & 16.1 & 38.6 & 2.4 \\
\hline
\end{tabular}

a Viscosimetric molecular weight.

b Melt flow index $(2,16 \mathrm{Kg} / 10 \mathrm{~min})$.

c Calculated by FTIR using $\mathrm{a}^{13} \mathrm{C}$ NMR calibration curve.

d Number-average of short branches per 1000 backbone carbons, [18,39] calculated using SSA curves.

e Weight-average of short branches per 1000 backbone carbons, [18,39] calculated using SSA curves.

${ }^{\mathrm{f}}$ Branches distribution index, calculated by $\mathrm{C}_{\mathrm{w}} / \mathrm{C}_{\mathrm{n}}$.
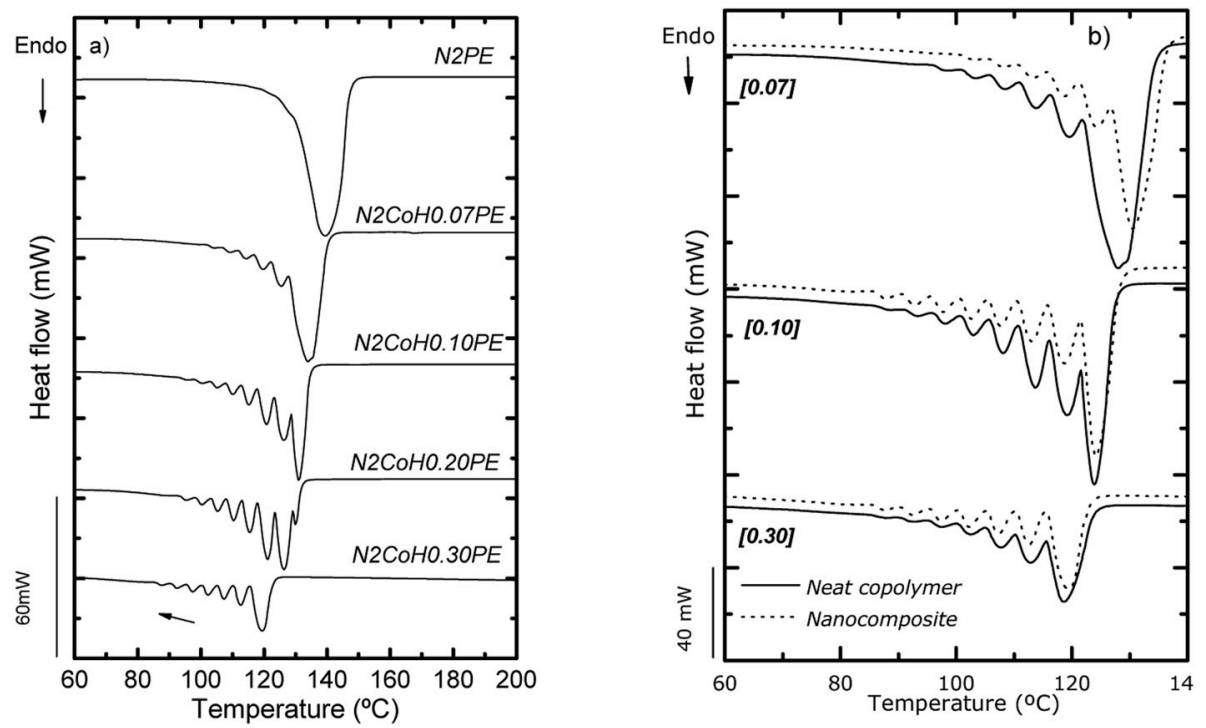

Fig. 5. SSA curves for a) nanocomposites with different amount of hexene, b) neat copolymer and their nanocomposites. 
can be demonstrated that copolymerization In situ of nanocomposites gives higher molecular weight and narrower distribution than neat copolymers, allowing more effective and organized incorporation of the branches and consequently a more homogeneous structure of the copolymer.

The results show that sepiolite increases productivity, improves the thermal stability of the catalyst and incorporates more efficiently, and orderly the comonomer in the structure of copolymer, increasing significantly the nanocomposite tenacity. However, Table 4 shows how the use of sepiolite produces a decrease in Young's modulus.

Only the sample N2CoH0.07 PE, filled with $3 \%$ of sepiolite, is capable to increase the module $20 \%$ but it loses $15 \%$ elongation at break with respect neat copolymer. These decreases in Young's modulus is produced by the incorporation of more branches and the decrease of final load due to the increase of productivity, thereby the nucleating and reinforcing effect of the nanoclay is shielded by the matrix properties. On the other hand, when raising the hexene amount, the elongation at break is improved for the nanocomposites. The sample with the most incorporation of short branches (N2CoH0.30 PE) had an elastomeric behavior.

Moreover, in Table 4, it can be observed an increase in tensile strength for nanocomposites as a result of good compatibility between the matrix and sepiolite. This fact is due to the capacity of the sepiolite to transmit the force and his resistance to being deformed.

Finally the presence of the clay is also reflected in the melt flow index and density (Tables 3 and 4). In general terms, the nanocomposites maintain a balance and there are no sudden drops in density or flowability even when they have large quantities of branches in their structure.

\subsection{PE/hexene nanocomposites: influence of the amount of sepiolite}

To evaluate the influence of the sepiolite in the polymerization, a series of nanocomposites were synthesized keeping constant the amount of hexene and varied amount of load. Table 5 summarizes the composition and thermal properties of synthesized copolymers.

It is evident how the enthalpy of fusion and crystallization in nanocomposites increased with small amounts of sepiolite which is produced by the "nucleating effect" of nanoclay. This phenomenon could be observed in DSC curves (Fig. 7), where low amounts of sepiolite increase the melting and crystallization temperature. However larger amounts of clay have the reverse effect and become a defect of the crystal system and the enthalpy of fusion decreases with an important loss in the crystallinity.

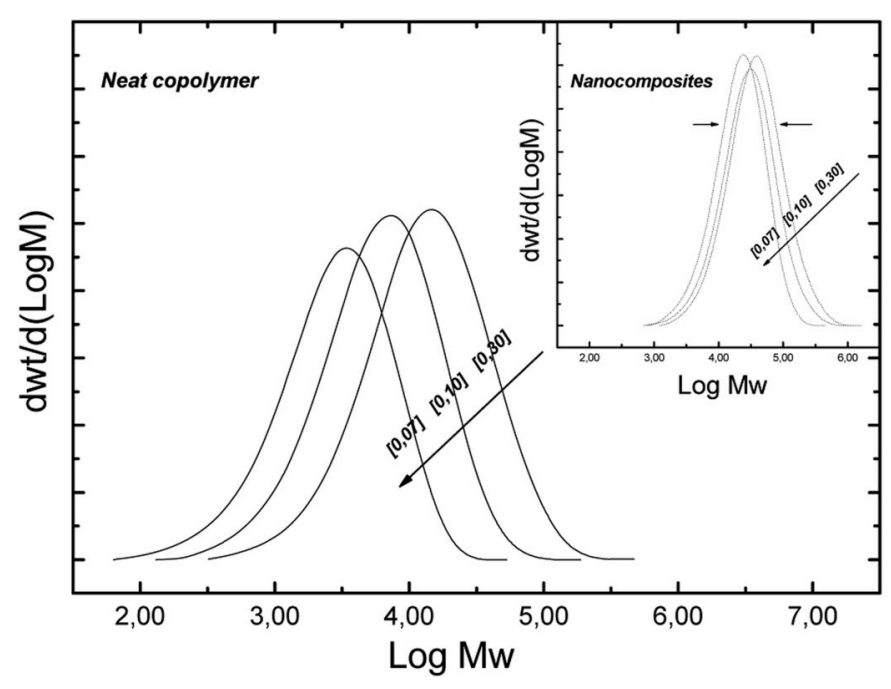

Fig. 6. GPC curves for the synthesized copolymers.
There is not a clear trend for productivity. The presence of a comonomer and the clay allows obtaining a larger amount of polymer. However, these effects compete with the deactivation of the catalyst due to the increase of hydroxyl groups of the load. For this reason, the sample N5CoH0.10 PE has an important drop in productivity and the percentage of final clay raises as the clay amount fed is raised.

In Table 6, the structural properties for the copolymers are given. The table shows that increasing the amount of sepiolite produced a rise of grafted comonomer and more homogeneous branching distribution.

This phenomenon has been evidenced in SSA curves (Fig. 8). It can be seen that the increase of sepiolite produces a reduction in enthalpy and a more homogeneous crystalline size distribution. Consequently, it can be said that the increase of clay produces copolymers with higher molecular weights and narrower short branching distribution, as it is shown by GPC results in Fig. 9. An increase in the amount of sepiolite it is also an increase of MAO in the polymerization medium as the ratio clay/MAO is 2:1; this represents a higher amount of actives centers available to start the polymerization process and consequently a bigger growth of the chains produced that are mainly controlled by propagation reaction leading to longer polymeric chains with higher molecular weights. Again, the termination reactions are hindered by the protective effect of the sepiolite. Also, it was demonstrated that the morphology of the fibrillar sepiolite promotes a significant increase in the length of the chains that grow over them [1], resulting ultimately in a highly hierarchical copolymer with a very ordered structure.

On the other hand, it has to be said that an increase in the amount of MAO represents an increase in reaction productivity, but also the increase in the amount of sepiolite is a rise in the concentration of $-\mathrm{OH}$ groups that promote the termination reaction. In this sense, there is a commitment of effects over the productivity of the polymerization process.

Also, in Table 6 it is evident that at high percentages of clay, the increase in the incorporation of short branches grows as it raises the amount of clay in the nanocomposites. This is because, at high percentages of clay, the highest incorporation of branches allowed in the reaction can be achieved.

The structure of the synthesized nanocomposites is reflected in their mechanical properties. The increase of sepiolite produces a rise in Young's modulus and decreases the elongation at break, which is the typical behavior of nanocomposites obtained by molten. These results are shown in Fig. 10.

This behavior is due to the way are found the branches in the copolymer structure, and also because of the crystalline sections formed are more regular in size and proportion, despite there are more branches in its structure.

\subsection{PE/octene nanocomposites: influence of the amount of octene}

A second experiment was carried out by changing the comonomer used. In this case, a series of PE/Octene copolymers were polymerized varying the amount of comonomer as in the previous case. Also, the nanocomposites were made to analyze the influence of the amount of sepiolite and the effect on their properties.

The presence of sepiolite enhances the thermal properties for the nanocomposites against the neat copolymers as shown in Table 7 . This evidence implies the "nucleating effect of the clay" is more effective on the matrix due to an increase in the length of the branches that promote greater mobility of the chains.

The PE/Octene nanocomposites are capable to increase their melting temperature up to $13^{\circ} \mathrm{C}$ when the amount of sepiolite is increased in the polymerization medium, as shown in Table 7 for the sample N5CoO0.10 PE against the neat copolymer without the clay.

This means that has occurred an important thickening of the lamellar thicknesses in the crystals formed. Despite this, there is not a rise in the number of crystalline populations due to the lack of important changes in the enthalpy of fusion. However, this property does not present 
Table 4

Mechanical properties for neat copolymers and their nanocomposites synthesized with different amounts of hexene.

\begin{tabular}{|c|c|c|c|c|c|c|c|c|}
\hline & Sample & $\mathrm{Ea}(\mathrm{MPa})$ & $\rho \mathrm{b}(\mathrm{g} / \mathrm{cm} 3)$ & Espc (Mpa.cm3/g) & erd (\%) & $\sigma \mathrm{fe}(\mathrm{MPa})$ & हyf (\%) & Tensile strength (MPa) \\
\hline \multirow[t]{5}{*}{ Neat Copolymers } & $P E$ & $985 \pm 37$ & $0,920 \pm 0,017$ & $1070 \pm 13$ & $524 \pm 12$ & $27 \pm 1$ & $12 \pm 2$ & $27 \pm 1$ \\
\hline & СoH0.07 PE & $884 \pm 19$ & $0,910 \pm 0,002$ & $972 \pm 10$ & $625 \pm 42$ & $26 \pm 1$ & $15 \pm 1$ & $26 \pm 1$ \\
\hline & СoH0.10 PE & $752 \pm 34$ & $0,890 \pm 0,025$ & $845 \pm 15$ & $698 \pm 28$ & $22 \pm 2$ & $15 \pm 1$ & $22 \pm 2$ \\
\hline & СoH0.20 PE & $831 \pm 25$ & $0,852 \pm 0,007$ & $709 \pm 13$ & $789 \pm 12$ & - & - & $19 \pm 1$ \\
\hline & СoHO.30 PE & $445 \pm 33$ & $0,821 \pm 0,049$ & $542 \pm 18$ & $820 \pm 41$ & - & - & $16 \pm 2$ \\
\hline \multirow[t]{5}{*}{ Nanocomposites } & $N 2 P E$ & $1351 \pm 32$ & $0,961 \pm 0,003$ & $1406 \pm 23$ & $508 \pm 19$ & $31 \pm 2$ & $9 \pm 2$ & $38 \pm 2$ \\
\hline & N2CoHO.O7 PE & $1051 \pm 23$ & $0,943 \pm 0,016$ & $1194 \pm 20$ & $512 \pm 32$ & $28 \pm 1$ & $15 \pm 1$ & $31 \pm 1$ \\
\hline & N2CoHO.1O PE & $721 \pm 28$ & $0,920 \pm 0,047$ & $784 \pm 14$ & $613 \pm 51$ & $35 \pm 1$ & $18 \pm 1$ & $27 \pm 2$ \\
\hline & $\mathrm{N} 2 \mathrm{CoHO} .2 \mathrm{OPE}$ & $556 \pm 17$ & $0,881 \pm 0,008$ & $631 \pm 17$ & $805 \pm 19$ & $17 \pm 1$ & $21 \pm 2$ & $22 \pm 1$ \\
\hline & N2CoHO.3O PE & $357 \pm 30$ & $0,846 \pm 0,036$ & $422 \pm 22$ & $1040 \pm 37$ & - & - & $20 \pm 1$ \\
\hline
\end{tabular}

a Young's modulus. ${ }^{\mathrm{b}}$ Density. ${ }^{\mathrm{c}}$ Specific modulus. ${ }^{\mathrm{d}}$ Failure elongation. ${ }^{\mathrm{e}}$ Failure stress. ${ }^{\mathrm{f}}$ Yield elongation.

Table 5

Composition and thermal properties of neat copolymer and nanocomposites with different amounts of sepiolite.

\begin{tabular}{|c|c|c|c|c|c|c|c|}
\hline & Sample $^{\mathrm{a}}$ & $\operatorname{Tm}\left(0,1 \pm^{\circ} \mathrm{C}\right)$ & $\operatorname{Tc}\left(0,1 \pm^{\circ} \mathrm{C}\right)$ & $\Delta \mathrm{Hm}(29 \pm \mathrm{J} / \mathrm{g})$ & $\mathrm{Xc}(0,1 \pm \%)$ & $\%$ clay & Productivity \\
\hline \multirow[t]{2}{*}{ Neat copolymer } & $P E$ & 139.8 & 108.0 & 284 & 96.9 & - & $8.51 \times 10^{3} \pm 4 \times 10^{2}$ \\
\hline & СoH0.10 PE & 124.7 & 104.3 & 208 & 79.8 & - & $1.37 \times 10^{4} \pm 5 \times 10^{2}$ \\
\hline \multirow[t]{4}{*}{ Nanocomposite } & $N 2 P E$ & 144.1 & 108.8 & 254 & 92.1 & $3.5 \pm 0.7$ & $9.12 \times 10^{3} \pm 6 \times 10^{3}$ \\
\hline & NO.5CoHO.1O PE & 132.4 & 107.9 & 238 & 82.1 & $0.9 \pm 0.3$ & $1.22 \times 10^{4} \pm 6 \times 10^{2}$ \\
\hline & N2CoHO.1OPE & 128.3 & 105.0 & 187 & 67.6 & $3.0 \pm 0.4$ & $1.57 \times 10^{4} \pm 9 \times 10^{2}$ \\
\hline & N5CoHO.1O PE & 123.9 & 103.1 & 163 & 52.7 & $8.9 \pm 0.1$ & $7.74 \times 10^{3} \pm 2 \times 10^{3}$ \\
\hline
\end{tabular}

${ }^{a}$ Nomenclature: PE: Polyethylene matrix, CoH0.10: hexene copolymer with $0.10 \mathrm{M}$ of initial hexene, N2: nanocomposite with $2 \mathrm{~g}$ of initial clay.
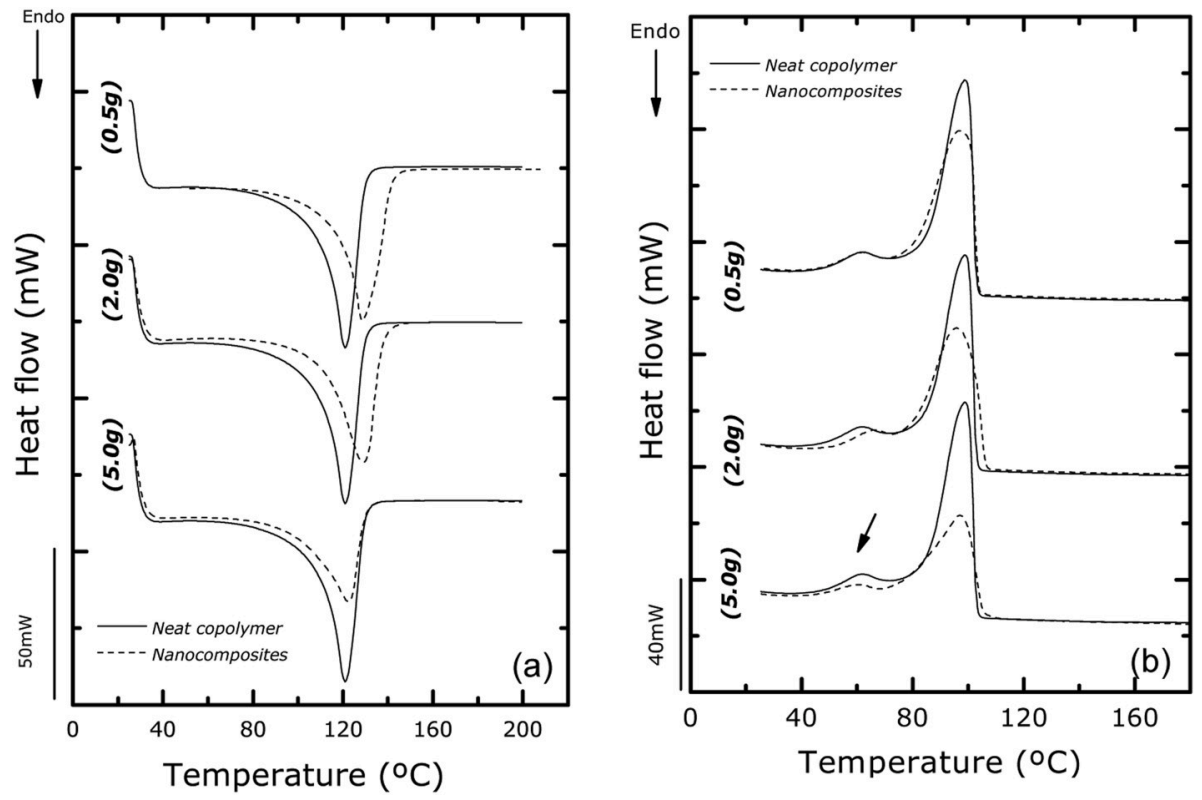

Fig. 7. DSC curves for a) fusion and b) crystallinization of neat copolymer PE/Hexene and their nanocomposites with different amounts of sepiolite.

significant losses, as shown in Fig. 11.

Regarding the relationship between the clay incorporated in the nanocomposite and the productivity, the $\mathrm{PE} /$ Octene nanocomposites follow the same trend as the PE/Hexene nanocomposites. When the comonomer concentration increase, the productivity also increases due to the already well-known "comonomer effect" and this brings together a greater dilution of the clay in the polymer synthesized. The PE/Octene nanocomposites present higher productivity than the PE/Hexene nanocomposites and a lower amount of final clay. This phenomenon may be due to the boiling points of both comonomers, the hexene has a boiling point of $64^{\circ} \mathrm{C}$ and the octene $120^{\circ} \mathrm{C}$ so that the octene remains longer in the liquid state in the polymerization medium and in turn, the "solubilization effect" is maintained for longer during the polymerization [40]. In spite of this, the double bond reactivity of the octene is lower than the hexene because of its chain length that interferes with the rate of incorporation. For this reason, even when the productivity is higher, the octene percentage in the nanocomposites is lower than the $\mathrm{PE} /$ Hexene nanocomposites as shown in Table 8.

Another important observation is that, as equal with the PE/Hexene nanocomposites, the sepiolite is capable of increasing the octene grafted and at the same time narrowing the branches distribution in the polymer structure (see Fig. 12). With a small amount of clay is evident how the $\mathrm{PE} /$ Octene nanocomposites equalize their crystalline populations. In this sense, the PE/Octene nanocomposites have a more homogeneous structure, high fluidity with small amounts of branches, and also a very little amount of load to obtain highly hierarchical and nanoreinforced structures.

Finally, in Fig. 13, it can be seen the influence of the comonomer 
Table 6

Structural characterization of neat copolymers and their nanocomposites with different amounts of sepiolite.

\begin{tabular}{|c|c|c|c|c|c|c|c|c|c|}
\hline & Sample & $\begin{array}{l}\operatorname{MFI}( \pm 0,3 \mathrm{~g} / \\
10 \mathrm{~min})^{\mathrm{a}}\end{array}$ & $\begin{array}{l}\% \text { molar Hexene } \\
( \pm 0,06)^{\mathrm{b}}\end{array}$ & $\begin{array}{l}\mathrm{Cn} \\
( \pm 0,02)^{\mathrm{c}}\end{array}$ & $\begin{array}{l}\text { Cw } \\
( \pm 0,02)^{\mathrm{d}}\end{array}$ & $\begin{array}{l}\text { BDI } \\
( \pm 0,9)^{\mathrm{e}}\end{array}$ & $\begin{array}{l}\operatorname{Mn}( \pm 0,3 \times 103 \\
\mathrm{g} / \mathrm{mol})\end{array}$ & $\begin{array}{l}\mathrm{Mw}( \pm 0,3 \times 104 \\
\mathrm{g} / \mathrm{mol})\end{array}$ & $\begin{array}{l}\text { P.I. } \\
( \pm 0,04)^{f}\end{array}$ \\
\hline \multirow[t]{2}{*}{ Neat copolymer } & $P E$ & 9.7 & 0.00 & - & - & - & $4.0 \times 10^{4}$ & $1.6 \times 10^{5}$ & 3.84 \\
\hline & СоHO.10 PE & 18.4 & 1.54 & 8.3 & 14.9 & 1.8 & $2.3 \times 10^{4}$ & $7.9 \times 10^{4}$ & 3.45 \\
\hline \multirow[t]{4}{*}{ Nanocomposite } & $N 2 P E$ & 7.3 & 0.00 & - & - & - & $5.9 \times 10^{4}$ & $1.9 \times 10^{5}$ & 3.20 \\
\hline & $\begin{array}{l}\text { NO.5CoHO.10 } \\
P E\end{array}$ & 17.8 & 1.98 & 9.1 & 13.7 & 1.5 & $3.7 \times 10^{4}$ & $1.0 \times 10^{5}$ & 2.79 \\
\hline & N2CoHO.1O PE & 16.4 & 2.25 & 12.3 & 16.0 & 1.3 & $5.9 \times 10^{4}$ & $1.6 \times 10^{5}$ & 2.67 \\
\hline & N5CoHO.1O PE & 12.1 & 2.33 & 14.5 & 16.1 & 1.1 & $7.1 \times 10^{4}$ & $1.6 \times 10^{5}$ & 2.21 \\
\hline
\end{tabular}

a Melt flow index $(2,16 \mathrm{Kg} / 10 \mathrm{~min})$.

b Calculated by FTIR using $\mathrm{a}^{13} \mathrm{C}$ NMR calibration curve.

c Number-average of short branches per 1000 backbone carbons, ${ }^{[18,39]}$ calculated using SSA curves.

d Weight-average of short branches per 1000 backbone carbons, ${ }^{[18,39]}$ calculated using SSA curves.

e Branches distribution index, calculated by $\mathrm{C}_{\mathrm{w}} / \mathrm{C}_{\mathrm{n}}$.

f P.I. polydispersity Index.

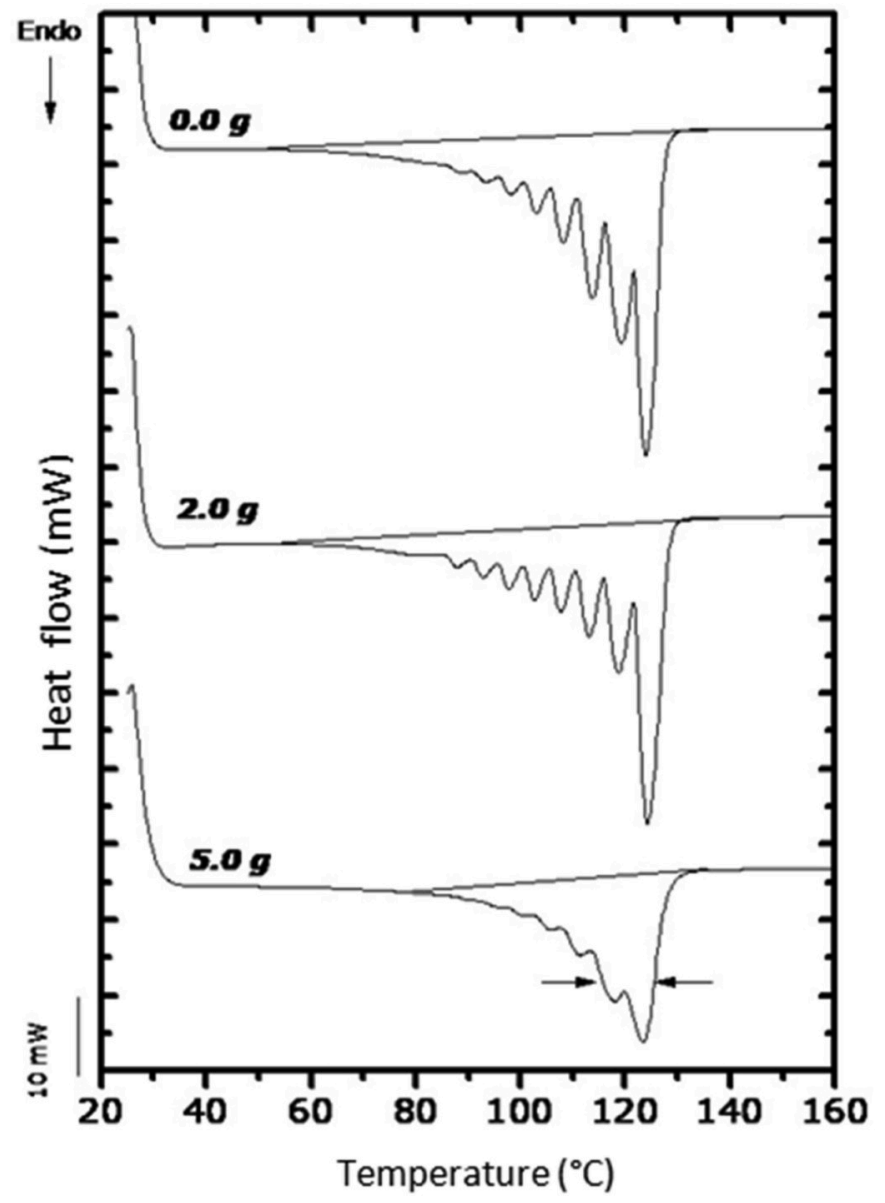

Fig. 8. SSA curves for PE/Hexene nanocomposites with different amounts of sepiolite.

concentrations and the amounts of sepiolite in the mechanical properties of the nanocomposites and the neat copolymers. With an increase in the comonomer concentration, there is a progressive loss of stiffness. However, in the presence of clay, this loss is reduced and less notable due to a minor presence of branches. Additionally, an important rise in Young's modulus is obtained when the amount of clay increased with a fixed comonomer concentration (more than $40 \%$ of increase with $3 \%$ of clay for the sample CoO0.10 PE against the neat copolymer).

It is important to note that this clay "stiffening effect" over the PE/ Octene copolymers does not affect the rubber-like behavior that these copolymers present. On the other hand, it can be observed that the loss

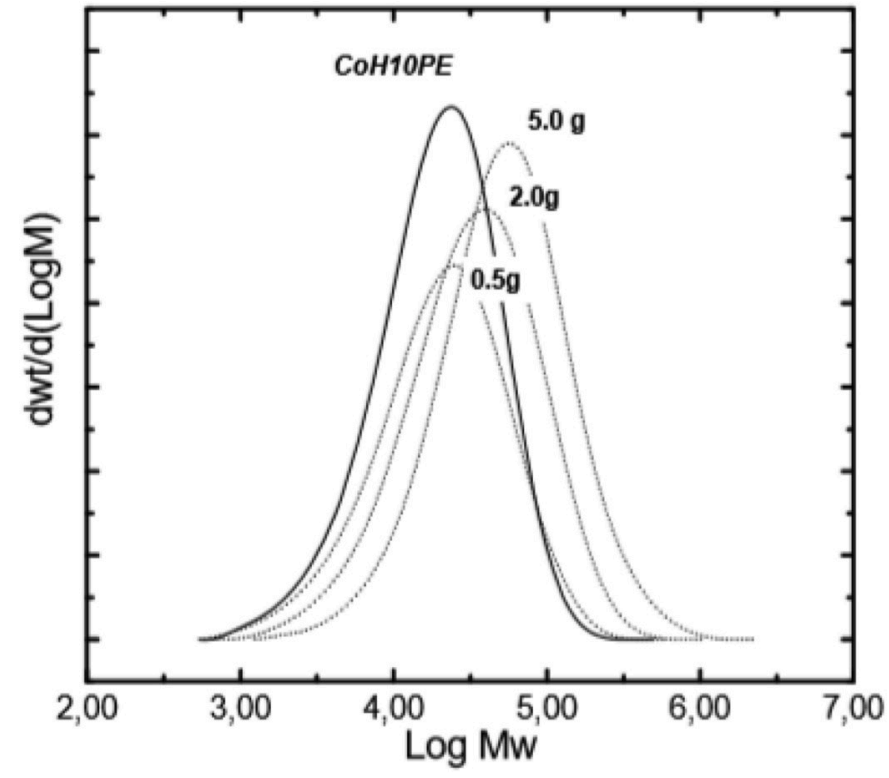

Fig. 9. GPC curves of the CoH0.10 PE copolymer and its nanocomposites with different amounts sepiolite concentrations.

in the elongation at break is around $12 \%$ in the sample with the highest amount of clay (N5CoO0.10 PE). This behavior is more attributed to the distribution of the short branches along the polymer chain than by the density of the branches and their length.

\subsection{Influence of the comonomer length}

A series of copolymers using decene as a comonomer were synthesized. These kinds of copolymers are very interesting because they can be molded as thermoplastics but have an "elastic" behavior in tensile and impact tests. Interpretation of the length of the branches is not easy because the type and branching distribution are varied simultaneously. Copolymers can have the same flow and density, but their molecular weight, distribution, and branch density could be different [9].

The copolymer PE/Decene was synthesized with a comonomer concentration of $0.10 \mathrm{M}$ and $2.0 \mathrm{~g}$ of modified sepiolite (2:1) for the nanocomposite. The structures of the copolymers are presented in Fig. 14 and the properties of these materials compared with nanocomposites in Table 9.

The incorporation of clay, as already explained, improves productivity. The trend decene $>$ octene $>$ hexene may be due to boiling temperatures of co-monomers. Octene $\left(120^{\circ} \mathrm{C}\right)$ and decene $\left(171^{\circ} \mathrm{C}\right)$ stay more time in a liquid state so the catalyst system could incorporate them 


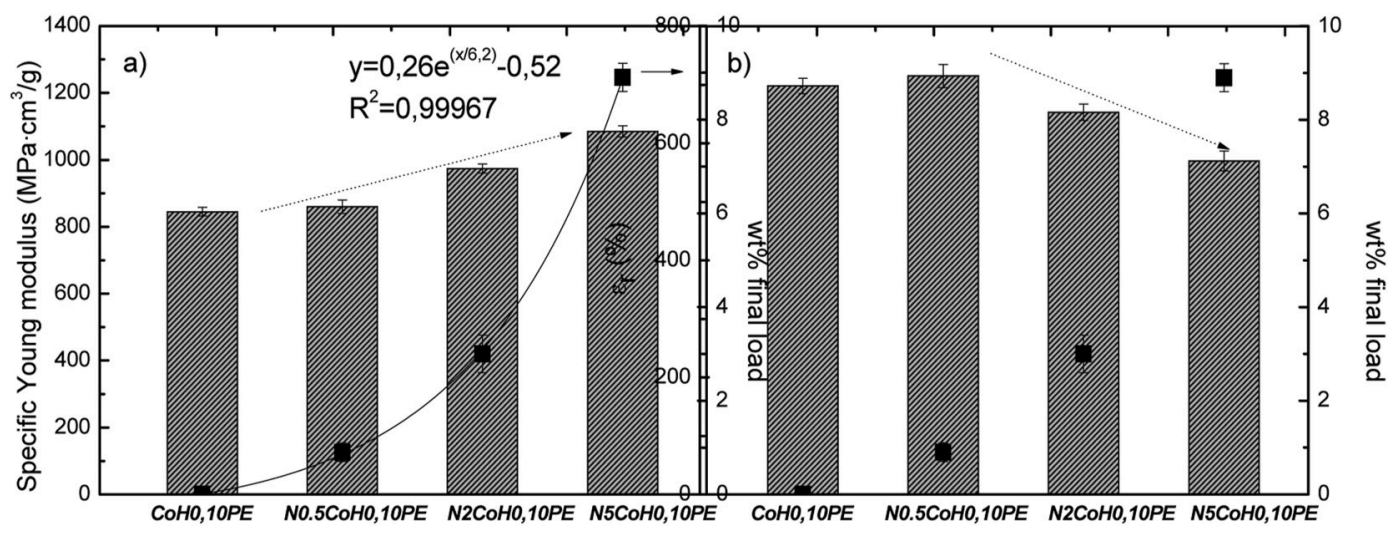

Fig. 10. a) Tensile strength and b) elongation at break of the PE/Hexene nanocomposites synthesized with different amounts of sepiolite.

Table 7

Composition and thermal properties of neat copolymers and nanocomposites with different amounts of octane and sepiolite.

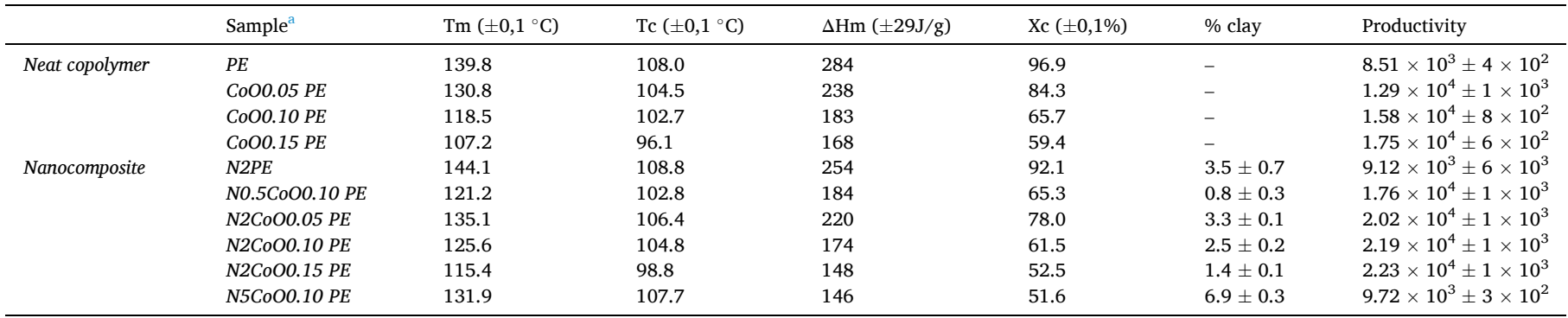

${ }^{a}$ Nomenclature: PE: Polyethylene matrix, CoO0.05:octene copolymer with $0.05 \mathrm{M}$ of initial octene, N2: nanocomposite with $2 \mathrm{~g}$ of initial clay.
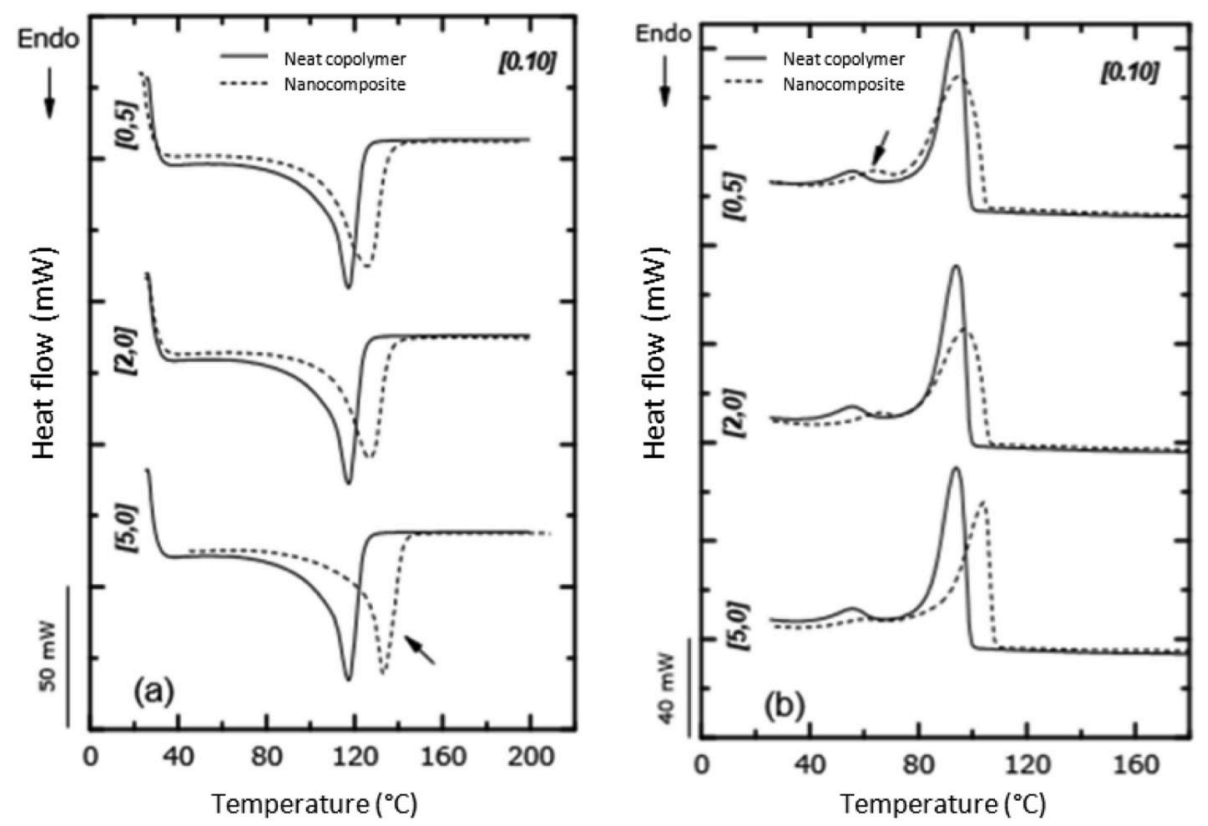

Fig. 11. DSC curves for a) fusion and b) crystallinization of neat copolymer PE/Octene and their nanocomposites with different amounts of sepiolite.

easier to growing chains, and, in consequence, increasing productivity. Other authors explain this fact because longer branches can increase the angle with the main chain, leaving space to continue with the addition of other monomers to the active complex, as shown in Fig. 14.[41]. The anomaly for N2CoD0.10 PE is produced by the decrease of sepiolite in the final polymer due to the rise of the comonomer length.

Another important observation is the fall of the melting temperatures in the copolymers with longer branches, this phenomenon could be associated with the less homogeneous structure of the final polymer as shown in Table 10. In like manner, decene copolymer, which incorporated fewer grafts, has the lower crystallinity. These results agree with Flory predictions who explained that melting temperatures and crystallinity of the copolymers are governed by density and distribution of the branches [42]. 
Table 8

Structural characterization of neat copolymers and their nanocomposites with different amounts of octane and sepiolite.

\begin{tabular}{|c|c|c|c|c|c|c|c|c|c|}
\hline & Sample ${ }^{\mathrm{a}}$ & $\begin{array}{l}\operatorname{MFI}( \pm 0,3 \mathrm{~g} / \\
10 \mathrm{~min})^{\mathrm{b}}\end{array}$ & $\begin{array}{l}\text { \% molar Octene } \\
( \pm 0,04)^{\mathrm{c}}\end{array}$ & $\begin{array}{l}\mathrm{Cn} \\
( \pm 0,02)\end{array}$ & $\begin{array}{l}\text { Cw } \\
( \pm 0,02)\end{array}$ & $\begin{array}{l}\text { BDI } \\
( \pm 0,03)\end{array}$ & $\begin{array}{l}\operatorname{Mn}( \pm 0,6 \times 103 \\
\mathrm{g} / \mathrm{mol})\end{array}$ & $\begin{array}{l}\mathrm{Mw}( \pm 0,4 \times 104 \\
\mathrm{g} / \mathrm{mol})\end{array}$ & $\begin{array}{l}\text { P.I. } \\
( \pm 0,05)^{d}\end{array}$ \\
\hline Neat & $P E$ & 9.7 & 0.00 & - & - & - & $4.0 \times 10^{4}$ & $1.6 \times 10^{5}$ & 3.84 \\
\hline \multirow[t]{3}{*}{ Copolymer } & CoOO.05 PE & 11.8 & 0.54 & 4.1 & 5.3 & 1.3 & $2.9 \times 10^{3}$ & $1.1 \times 10^{4}$ & 3.96 \\
\hline & CoOO.10 PE & 19.4 & 1.35 & 5.6 & 8.9 & 1.6 & $2.1 \times 10^{3}$ & $9.0 \times 10^{3}$ & 4.30 \\
\hline & CoOO.15 PE & 22.8 & 2.79 & 6.8 & 12.9 & 1.9 & $1.1 \times 10^{3}$ & $5.1 \times 10^{3}$ & 4.56 \\
\hline \multirow[t]{7}{*}{ Nanocomposite } & N2PE & 7.3 & 0.00 & - & - & - & $5.9 \times 10^{4}$ & $1.9 \times 10^{5}$ & 3.20 \\
\hline & N0.5CoO0.10 & 12.8 & 1.48 & 5.8 & 8.1 & 1.4 & $3.5 \times 10^{3}$ & $1.4 \times 10^{4}$ & 4.01 \\
\hline & $P E$ & & & & & & & & \\
\hline & N2CoOO.05 PE & 10.1 & 0.89 & 4.8 & 5.3 & 1.1 & $6.1 \times 10^{3}$ & $1.9 \times 10^{4}$ & 3.24 \\
\hline & N2CoOO.10 PE & 14.7 & 1.97 & 5.9 & 7.0 & 1.2 & $4.2 \times 10^{4}$ & $1.5 \times 10^{4}$ & 3.67 \\
\hline & N2CoOO.15 PE & 20.4 & 3.11 & 7.1 & 10.6 & 1.5 & $2.6 \times 10^{4}$ & $8.3 \times 10^{3}$ & 4.18 \\
\hline & N5CoOO.10 PE & 10.5 & 2.02 & 6.2 & 5.5 & 0.9 & $8.9 \times 10^{3}$ & $2.5 \times 10^{4}$ & 2.84 \\
\hline
\end{tabular}

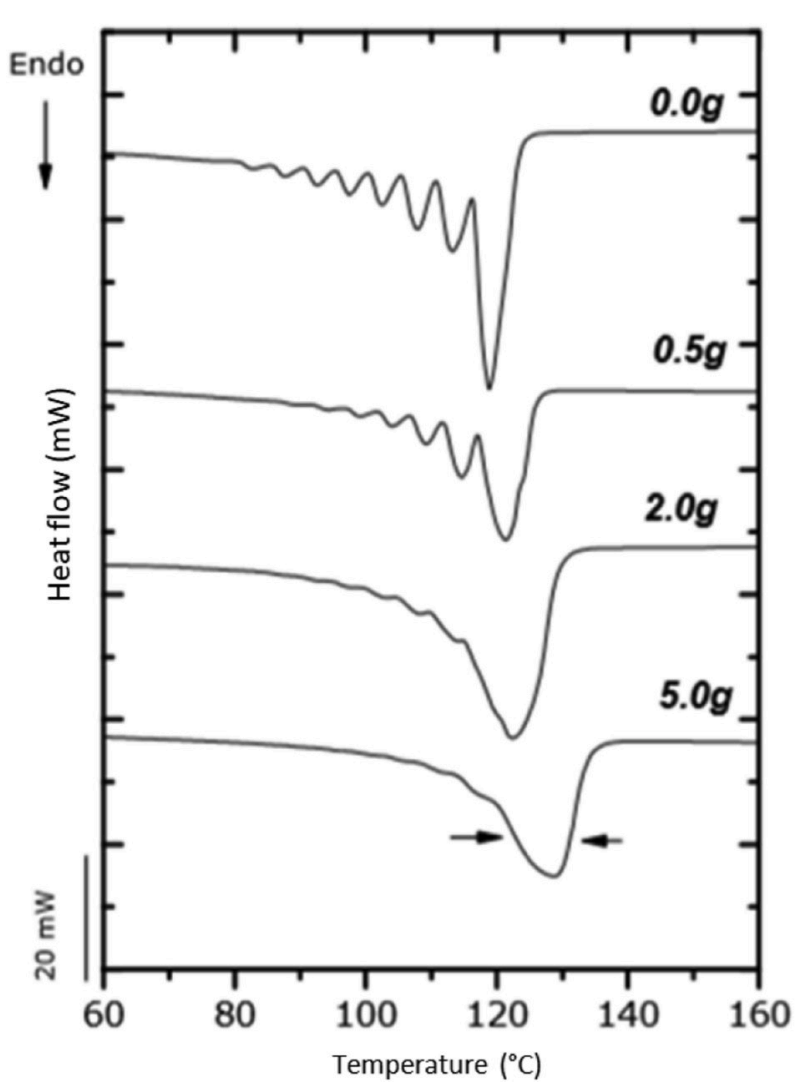

Fig. 12. SSA curves for PE/Octene nanocomposites with different amounts of sepiolite.

It is noted that the polydispersity index for the copolymers was higher than the values commonly reported for this polymerization process and this is attributed to our non-isothermal polymerization method that was designed to give higher activation energy of the catalysts during the polymerization reaction and allows to obtain a broaden molar mass distribution regardless the comonomer added. With this approach, it is possible to obtain a balance between the mechanical and rheological properties of the synthesized material thanks to the benefits of a combination of high, and low, molecular weight chains. In this sense, the fluency is improved with excellent mechanical properties. This represents a key strategy to improve the nanoclay's effect on the molecular weight of the polyethylene matrix.

Fig. 15 shows the mechanical properties of the synthesized materials. It can be seen how the increase of length branches decreases the Young' modulus values and there is not an important enhancement of tenacity.

Regarding the nanocomposites, the incorporation of clay in the polymerization medium is a solution to regulate the incorporation of
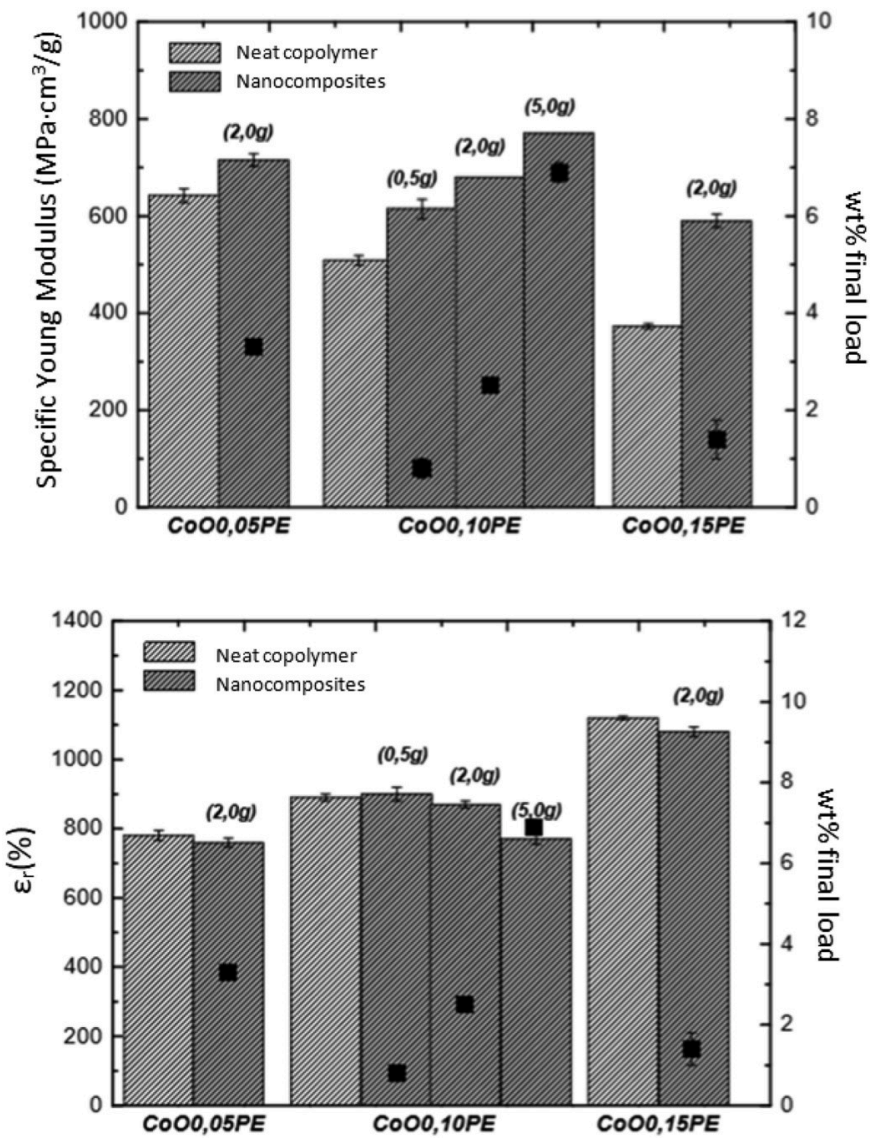

Fig. 13. a) Tensile strength and b) elongation at break of the PE/Octene nanocomposites synthesized with different amounts of comonomer and sepiolite.

branches. In these cases, improvements in stiffness and toughness are presented against the neat copolymers, and therefore stable their melting temperatures.

\section{Conclusion}

PE copolymers loaded with sepiolite have been successfully prepared. The results of this research have shown the advantages of using In situ polymerization to obtain copolymer nanocomposites. The presence of modified sepiolite can regulate a rise of grafted comonomer and more homogeneous branching distribution. Also, the sepiolite can reduce the enthalpy and produces more homogeneous crystalline sizes.

It is important to note that when the comonomer concentration is increased, the molecular weight is decreased for each neat copolymer 


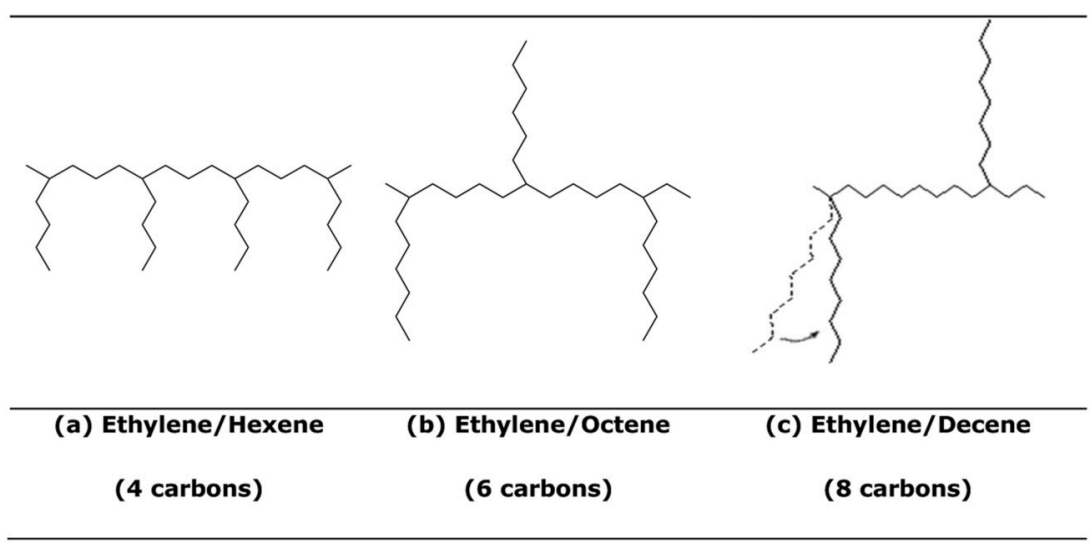

Fig. 14. Representation of the branches in the polyethylene backbone for the synthesized copolymers.

Table 9

Composition and thermal properties of neat copolymer and nanocomposites with different comonomer length.

\begin{tabular}{|c|c|c|c|c|c|c|c|}
\hline & Samplea & $\operatorname{Tm}\left( \pm 0,1^{\circ} \mathrm{C}\right)$ & Tc $\left( \pm 0,1^{\circ} \mathrm{C}\right)$ & $\Delta \mathrm{Hm}( \pm 29 \mathrm{~J} / \mathrm{g})$ & Xc $( \pm 0,1 \pm \% \%)$ & $\%$ clay & Productivity \\
\hline \multirow[t]{4}{*}{ Neat copolymer } & $P E$ & 139.8 & 108.0 & 284 & 96.9 & - & $8.51 \times 10^{3} \pm 4 \times 10^{2}$ \\
\hline & СoHO.10 PE & 126.4 & 105.1 & 229 & 85.8 & - & $9.73 \times 10^{3} \pm 2 \times 10^{2}$ \\
\hline & CoOO.10 PE & 118.5 & 102.7 & 183 & 65.7 & - & $1.58 \times 10^{4} \pm 8 \times 10^{2}$ \\
\hline & CoD0.10 PE & 112.9 & 102.1 & 175 & 62.1 & - & $1.79 \times 10^{4} \pm 5 \times 10^{2}$ \\
\hline \multirow[t]{4}{*}{ Nanocomposites } & N2PE & 144.1 & 108.8 & 254 & 92.1 & $3.5 \pm 0.7$ & $9.12 \times 10^{3} \pm 6 \times 10^{3}$ \\
\hline & N2CoHO.10 PE & 128.3 & 105.5 & 187 & 67.6 & $3.0 \pm 0.4$ & $1.44 \times 10^{4} \pm 9 \times 10^{2}$ \\
\hline & N2CoOO.10 PE & 125.6 & 104.8 & 174 & 61.5 & $2.5 \pm 0.2$ & $2.19 \times 10^{4} \pm 1 \times 10^{3}$ \\
\hline & N2CoD0.10 PE & 116.5 & 105.4 & 171 & 57.8 & $1.3 \pm 0.4$ & $2.08 \times 10^{4} \pm 3 \times 10^{2}$ \\
\hline
\end{tabular}

Table 10

Composition of the neat copolymer and their nanocomposites using different length comonomers.

\begin{tabular}{|c|c|c|c|c|c|c|}
\hline & Sample & $\operatorname{MFI}( \pm 0,5 \mathrm{~g} / 10 \mathrm{~min}) \mathrm{b}$ & M\% of Copolymer $( \pm 0,04)$ & $\operatorname{Mn}( \pm 0,6 \times 103 \mathrm{~g} / \mathrm{mol})$ & $\mathrm{Mw}( \pm 0,3 \times 103 \mathrm{~g} / \mathrm{mol})$ & P.I. . $( \pm 0,03) c$ \\
\hline \multirow[t]{4}{*}{ Neat Copolymer } & $\mathrm{PE}$ & 9.7 & 0.00 & $4.0 \times 10^{4}$ & $1.6 \times 10^{5}$ & 3.84 \\
\hline & CoH0.10 PE & 18.4 & 1.54 & $2.2 \times 10^{3}$ & $8.6 \times 10^{3}$ & 3.95 \\
\hline & CoO0.10 PE & 19.4 & 1.35 & $2.1 \times 10^{3}$ & $9.0 \times 10^{3}$ & 4.30 \\
\hline & CoD0.10 PE & 15.1 & 0.98 & $1.9 \times 10^{3}$ & $9.0 \times 10^{3}$ & 4.75 \\
\hline \multirow[t]{4}{*}{ Nanocomposite } & $\mathrm{N} 2 \mathrm{PE}$ & 7.3 & 0.00 & $5.9 \times 10^{4}$ & $1.9 \times 10^{5}$ & 3.20 \\
\hline & N2CoH0.10 PE & 16.4 & 2.25 & $2.2 \times 10^{4}$ & $6.5 \times 10^{4}$ & 3.44 \\
\hline & $\mathrm{N} 2 \mathrm{CoO} 0.10 \mathrm{PE}$ & 14.7 & 1.97 & $4.2 \times 10^{4}$ & $1.5 \times 10^{4}$ & 3.67 \\
\hline & N2CoD0.10 PE & 12.9 & 1.98 & $1.4 \times 10^{3}$ & $5.4 \times 10^{3}$ & 3.89 \\
\hline
\end{tabular}

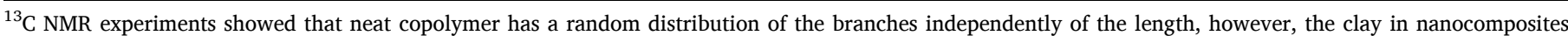
produces narrower distributions and the increase of grafted co-monomer, as shown in Table 11.

Table 11

Branch distribution of the neat copolymer and their nanocomposites using different length comonomers.

\begin{tabular}{|c|c|c|c|c|c|c|c|}
\hline & \multirow[t]{2}{*}{ Sample } & \multicolumn{6}{|c|}{ Triads (comonomer distribution $\pm 0,001)^{\mathrm{a}}$} \\
\hline & & EEE & CEE & ECE & CEC & ECC & CCC \\
\hline \multirow[t]{4}{*}{ Neat Copolymer } & PE & - & - & - & - & - & - \\
\hline & CoH0.10 PE & 0.589 & 0.254 & 0.157 & 0.000 & 0.000 & 0.000 \\
\hline & CoO0.10 PE & 0.574 & 0.357 & 0.034 & 0.010 & 0.025 & 0.000 \\
\hline & CoD0.10 PE & 0.347 & 0.276 & 0.052 & 0.201 & 0.124 & 0.000 \\
\hline \multirow[t]{4}{*}{ Nanocomposite } & N2PE & - & - & - & - & - & - \\
\hline & N2CoH0.10 PE & 0.245 & 0.457 & 0.262 & 0.036 & 0.000 & 0.000 \\
\hline & N2CoO0.10 PE & 0.270 & 0.463 & 0.150 & 0.078 & 0.038 & 0.000 \\
\hline & N2CoD0.10 PE & 0.456 & 0.258 & 0.165 & 0.096 & 0.025 & 0.000 \\
\hline
\end{tabular}

${ }^{\text {a }}{ }^{13} \mathrm{C}$ NMR results where $\mathrm{E}$ is the ethylene monomer and $\mathrm{C}$ is the grafted comonomer.

and its nanocomposite due to transfer and termination reactions that promote the grafted branches. However this effect, for the nanocomposites, is lower because the clay can protect the polymerization against the transfer and termination reactions.

The presence of the sepiolite enhances the thermal properties for the nanocomposites against the neat copolymers due to the "nucleating effect of the clay". This effect is more effective with an increase in the length of the branches that promote greater mobility of the chains. On the other hand, it has been observed a drop in the melting temperatures in the copolymers with longer branches associated with the heterogeneous structure of the final polymer. Also, it has been evidenced by the well-known "comonomer effect" due to an increase in productivity when 

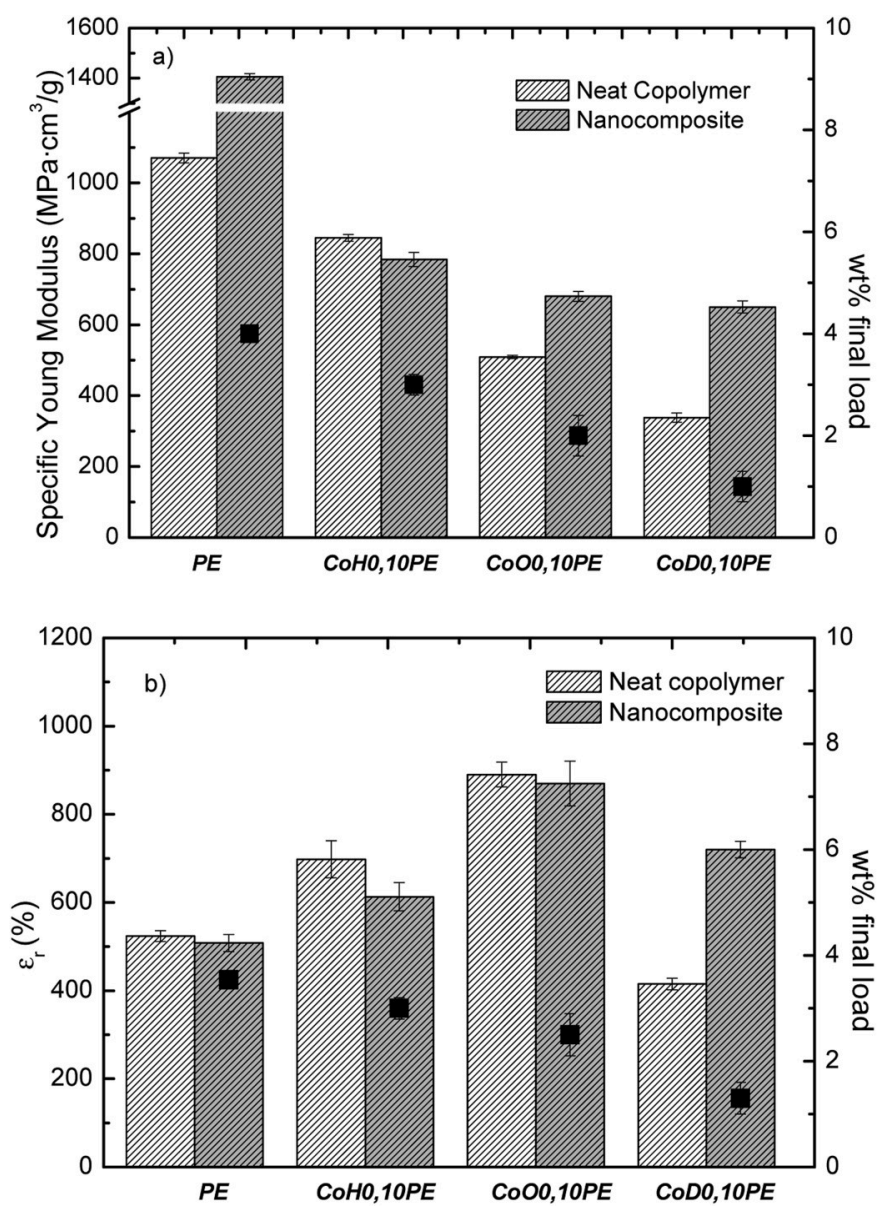

Fig. 15. a) Tensile strength and b) elongation at break of the neat copolymers and their nanocomposites synthesized with comonomers of different length chain.

the comonomer concentration increase.

The incorporation of clay in the polymerization medium is a solution to regulate the incorporation of branches. Improvements in stiffness and toughness are presented against the neat copolymers.

The neat copolymers and their nanocomposites have been characterized in thermal behavior and mechanical test. The versatility of this method allows manufacturing from ultra-high molecular weight polyethylene up to thermoplastic rubbers.

\section{Declaration of competing interest}

The authors declare that they have no known competing financial interests or personal relationships that could have appeared to influence the work reported in this paper.

\section{CRediT authorship contribution statement}

Paolo Tanasi: Writing - review \& editing, Visualization. María Asensio: Validation. Manuel Herrero: Writing - original draft. Karina Núñez: Methodology, Investigation, Formal analysis, Data curation. Esteban Cañibano: Resources, Project administration. Juan Carlos Merino: Conceptualization, Funding acquisition.

\section{Acknowledgements}

The authors acknowledge the financial support of "Ministerio de Economía y Competitividad - Spain" through the project MAT201785101-C2-2-R.

\section{Appendix A. Supplementary data}

Supplementary data to this article can be found online at https://doi. org/10.1016/j.polymer.2020.122707.

\section{References}

[1] M. Herrero, K. Núñez, R. Gallego, J.C. Merino, J.M. Pastor, Control of molecular weight and polydispersity in polyethylene/needle-like shaped clay nanocomposites obtained by in situ polymerization with metallocene catalysts, Eur. Polym. J. 75 (2016) 125-141, https://doi.org/10.1016/j.eurpolymj.2015.12.005.

[2] S. Fu, Z. Sun, P. Huang, Y. Li, N. Hu, Some basic aspects of polymer nanocomposites: a critical review, Nano Materials Science 1 (2019) 2-30, https:// doi.org/10.1016/j.nanoms.2019.02.006.

[3] F. Guo, S. Aryana, Y. Han, Y. Jiao, A review of the synthesis and applications of polymer-nanoclay composites, Appl. Sci. 8 (2018) 1696, https://doi.org/10.3390/ app8091696.

[4] M. SmiT, X. Zheng, R. Brüll, J. Loos, J.C. Chadwick, C.E. Koning, Effect of 1-hexene comonomer on polyethylene particle growth and copolymer chemical composition distribution, J. Polym. Sci. Polym. Chem. 44 (2006) 2883-2890, https://doi.org/ 10.1002/pola.21399.

[5] Bunjerd Jongsomjit, Paninee Kaewkrajang, Piyasan Praserthdam, Effect of silanemodified silica/MAO-supported Et[Ind] 2ZrCl 2 metallocene catalyst on copolymerization of ethylene, Eur. Polym. J. 40 (2004) 2813-2817, https://doi. org/10.1016/j.eurpolymj.2004.06.023.

[6] Li Kuo-Tseng \& Dai, Chi-Lun \& Kuo, Cheng-Wei, Ethylene polymerization over a nano-sized silica supported $\mathrm{Cp} 2 \mathrm{ZrCl} 2 / \mathrm{MAO}$ catalyst, Catal. Commun. 8 (2007) 1209-1213, https://doi.org/10.1016/j.catcom.2006.11.011.

[7] K. Soga, H.J. Kim, T. Shiono, Polymerization of propene with highly isospecific. $\mathrm{SiO} 2$-supported zirconocene catalysts activated with common alkylaluminiums, Macromol. Chem. Phys. 195 (1994) 3347-3360, https://doi.org/10.1002/ macp.1994.021951006.

[8] Michael Alexandre, Eric Martin, Philippe Dubois, Miguel Garcia-Marti, Robert Jérôme, Use of metallocenes in the polymerization-filling technique with production of polyolefin-based composites, Macromol. Rapid Commun. 21 (2000) 931-936, https://doi.org/10.1002/1521-3927(20000801)21:13\%3C931::AIDMARC931\%3E3.0.CO;2-X.

[9] H. Hong, Z. Zhang, T.C.M. Chung, R.W. Lee, Synthesis of new 1-decene-based LLDPE resins and comparison with the corresponding 1-octene- and 1-hexenebased LLDPE resins, J. Polym. Sci. Polym. Chem. 45 (2007) 639-649, https://doi. org/10.1002/pola.21825.

[10] W. Kaminsky, C. Piel, K. Scharlach, Polymerization of ethene and longer chained olefins by metallocene catalysis, Macromol. Symp. 226 (2005) 25-34, https://doi. org/10.1002/masy.200550803.

[11] W. Kaminsky, The discovery of metallocene catalysts and their present state of the art, J. Polym. Sci. Polym. Chem. 42 (2004) 3911-3921, https://doi.org/10.1002/ pola.20292.

[12] R. Mülhaupt, Catalytic polymerization and post polymerization catalysis fifty years after the discovery of ziegler's catalysts, Macromol. Chem. Phys. 204 (2003) 289-327, https://doi.org/10.1002/macp.200290085.

[13] A.J.D. Freitas, J.H.Z. Santos, S.M.P. Meneghetti, M.R. Meneghetti, Polymerization of ethylene: some aspects of metallocene catalyst stabilization under homogeneous and heterogeneous reaction conditions, J. Appl. Polym. Sci. 119 (2011) 3051-3057, https://doi.org/10.1002/app.33058.

[14] K.T. Li, C.L. Dai, C.Y. Li, Polymer Bulletin, Synthesis of linear low density polyethylene with a nano-sized silica supported $\mathrm{Cp}_{2} \mathrm{ZrCl}_{2} / \mathrm{MAO}$ catalyst. htt ps://doi.org/10.1007/s00289-009-0167-3, 2010, 64, 749-759.

[15] A. Alikhanil, S. Hakim1, M. Nekoomanesh, Modifed preparation of HDPE/clay nanocomposite by in situ polymerization using a metallocene catalyst, Iran. Polym. J. (Engl. Ed.) 26 (2017) 721-731, https://doi.org/10.1007/s13726-017-0557-6.

[16] N. Sharma, H. Ojha, A. Bharadwaj, D. Pathak, R. Sharma, Preparation and catalytic applications of nanomaterials: a review, RSC Adv. 5 (2015) 53381-53403, https:// doi.org/10.1039/C5RA06778B.

[17] K. Nuñez, R. Gallego, J.C. Merino, J.M. Pastor, The structure of sepiolite as support of metallocene co-catalyst during in situ polymerization of polyolefin (nano) composites, Appl. Clay Sci. 101 (2014) 73-81, https://doi.org/10.1016/j. clay.2014.07.020.

[18] C. Piel, P. Starck, J.V. Seppälä, W. Kaminsky, Thermal and mechanical analysis of metallocene-catalyzed ethene- $\alpha$-olefin copolymers: the influence of the length and number of the crystallizing side chains, J. Polym. Sci. Polym. Chem. 44 (2006) 1600-1612, https://doi.org/10.1002/pola.21265.

[19] The Physical-Chemical Properties of Sepiolite Were Privately provided by TOLSA.

[20] M. Asensio, M. Herrero, K. Núñez, R. Gallego, J.C. Merino, J.M. Pastor, In situ polymerization of isotactic polypropylene sepiolite nanocomposites and its copolymers by metallocene catalysis, Eur. Polym. J. 100 (2018) 278-289, https:// doi.org/10.1016/j.eurpolymj.2018.01.034.

[21] A. Niemczyk, K. Dziubek, B. Sacher-Majewska, K. Czaja, M. Dutkiewicz, B. Marciniec, Study of thermal properties of polyethylene and polypropylene nanocomposites with long alkyl chain-substituted POSS fillers, J. Therm. Anal Calorim. 125 (2016) 1287-1299, https://doi.org/10.1007/s10973-016-5497-4.

[22] B. Fillon, J.C. Wittmann, B. Lotz, A. Thierry, Self-nucleation and recrystallization of isotactic polypropylene ( $\alpha$ phase) investigated by differential scanning calorimetry, J. Polym. Sci. B Polym. Phys. 31 (1993) 1383-1393, https://doi.org/10.1002/ polb.1993.090311013. 
[23] A.J. Müller, Z.H. Hernández, M.L. Arnal, J.J. Sánchez, Successive, self-nucleation/ annealing (SSA): a novel technique to study molecular segregation during crystallization, Polym. Bull. 39 (1997) 465-472, https://doi.org/10.1007/ s002890050174.

[24] M.L. Arnal, V. Balsamo, G. Ronca, A. Sánchez, A.J. Müller, E. Cañizales, C. Urbina de Navarro, Applications of successive self-nucleation and annealing (SSA) to polymer characterization, J. Therm. Anal. Calorim. 59 (2000) 451-470, https:// doi.org/10.1023/A:1010137408023.

[25] A.J. Müller, M.L. Arnal, Thermal fractionation of polymers, Prog. Polym. Sci. 30 (2005) 559-603, https://doi.org/10.1016/j.progpolymsci.2005.03.001.

[26] A.J. Müller, R. Michell, R. Pérez, A. Lorenzo, Successive Self-nucleation and Annealing (SSA): correct design of thermal protocol and applications, Eur. Polym. J. 65 (2015) 132-154, https://doi.org/10.1016/j.eurpolymj.2015.01.015.

[27] C. Ding, G. Zhang, J. Gu, F. Cao, X. Zheng, Application of the correct design of successive self-nucleation and annealing (SSA) to study the stereo-defects and its distribution of homo- and co-polypropylene, RSC Adv. 7 (2017) 24870-24877, https://doi.org/10.1039/C7RA03301J.

[28] M. Pracella, A. D’Alessio, S. Giaiacopi, A. Raspolli Galletti, C. Carlini, G. Sbrana, FTIR microanalysis and phase behaviour of ethylene/1-hexene random copolymers, Macromol. Chem. Phys. 14 (2007) 1560-1571, https://doi.org/ 10.1002/macp. 200700028.

[29] Q. Wu, A. García-Peñas, R. Barranco-García, M.L. Cerrada, R. Benavente, E. Pérez, J.M. Gómez-Elvira, A new insight into the comonomer effect through NMR analysis in metallocene catalysed propene-co-1-nonene copolymers, Polymers 11 (2019) 1266, https://doi.org/10.3390/polym11081266.

[30] B. Jiang, X. Liu, Y. Weng, Z. Fu, A. He, Z. Fan, Mechanistic study on comonomer effect in ethylene/1-hexene copolymerization with $\mathrm{TiCl}_{4} / \mathrm{MgCl}_{2}$ model ZieglerNatta catalysts, J. Catal. 369 (2019) 324-334, https://doi.org/10.1016/j. jcat.2018.11.034.

[31] F. Bortolussi, J. Broyer, R. Spitz, C. Boisson, Synthesis of silica-supported metallocene catalysts for olefin polymerization, Macromol. Chem. Phys. 203 (2003) 2501-2507, https://doi.org/10.1002/macp.200290032.

[32] Y. Ko, I. Seong, Shape and diffusion of the monomer-controlled copolymerization of ethylene and $\alpha$-olefins over $\mathrm{Cp}_{2} \mathrm{ZrCl}_{2}$ confined in the nanospace of the supercage of NaY, J. Polym. Sci. Polym. Chem. 41 (2003) 2171-2179, https://doi.org/ 10.1002/pola.10762.
[33] P. Kumkaew P, L. Wu, P. Praserthdam, S. Wanke, Rates and product properties of polyethylene produced by copolymerization of 1 -hexene and ethylene in the gas phase with (n-BuCp)2ZrCl2 on supports with different pore sizes, Polymer 44 (2003) 4791-4803, https://doi.org/10.1016/s0032-3861(03)00473-7.

[34] J.M. Zhou, N.H. Li, N.Y. Bu, D. Lynch, S. Wanke, Gas-phase ethylene polymerization over polymer-supported metallocene catalysts, J. Appl. Polym. Sci. 90 (2003) 1319-1330, https://doi.org/10.1002/app.12773.

[35] J.A.M. Awudza, P.J.T. Tait, The "comonomer effect" in ethylene/ $\alpha$-olefin copolymerization using homogeneous and silica-supported $\mathrm{Cp}_{2} \mathrm{ZrCl}_{2} / \mathrm{MAO}$ catalyst systems: some insights from the kinetics of polymerization, active center studies, and polymerization temperature, J. Polym. Sci. Polym. Chem. 46 (2008) 267-277, https://doi.org/10.1002/pola.22378.

[36] H. Yang, L. Zhang, Z. Fu, Z. Fan, Comonomer effects in copolymerization of ethylene and 1-hexene with $\mathrm{MgCl}_{2}$-supported Ziegler-Natta catalysts: new evidences from active center concentration and molecular weight distribution, J. Appl. Polym. Sci. 132 (2014) 41264, https://doi.org/10.1002/app.41264.

[37] L. Cui, H. Cho, J. Shin, N. Tarte, S. Woo, Polyethylene-Montmorillonite Nanocomposites: Preparation, Characterization and Properties, in: Macromolecular Symposia, vol. 260, 2008, pp. 49-57, https://doi.org/10.1002/masy.200751408.

[38] M. Wannaborworn, P. Praserthdam, B. Jongsomjit, Observation of different catalytic activity of various 1-olefins during ethylene/1-olefin copolymerization with homogeneous metallocene catalysts, Molecules 16 (2011) 373-383, https:// doi.org/10.3390/molecules16010373.

[39] S.R. Torabi, N. Fazeli, A rapid quantitative method for determination of short chain branching content and branching distribution index in LLDPEs by DSC, Polym. Test. 28 (2009) 866-870, https://doi.org/10.1016/j.polymertesting.2009.07.009, 28.

[40] B. Paredes, J.B. P Soares, R. van Greiken, A. Carrero, I. Suarez, Characterization of Ethylene-1-Hexene Copolymers Made with Supported Metallocene Catalysts: Influence of Support Type, in: Macromolecular Symposia, vol. 257, 2007, pp. 103-111, https://doi.org/10.1002/masy.200751109.

[41] T.S. Halbach, Y. Thomann, R. Mülhaupt, Boehmite nanorod-reinforcedpolyethylenes and ethylene/1-octene thermoplastic elastomer nanocomposites prepared by in situ olefin polymerization and melt compounding, J. Polym. Sci. Polym. Chem. 46 (2008) 2755-2765, https://doi.org/10.1002/pola.22608.

[42] P.J. Flory, Theory of crystallization in copolymers, Trans. Faraday Soc. 51 (1955) 848-857, https://doi.org/10.1039/TF9555100848. 